\title{
Complutum
}

ISSN: 1131-6993

\section{Dientes de hoz, hoces y Edad del Bronce: la contribución de un programa experimental de $\operatorname{siega}^{1}$}

\author{
Francisco Javier Jover Maestre²; Amelia Rodríguez Rodríguez ${ }^{3}$; Palmira Torregrosa Giménez ${ }^{4}$
}

Resumen. Aunque los denominados como dientes de hoz son bien conocidos en todos sus aspectos morfológicos, tecnológicos y funcionales, se consideró necesario el desarrollo de un nuevo programa de arqueología experimental con el objetivo de validar algunas de las hipótesis hasta ahora planteadas en la bibliografía específica y profundizar en el estudio de las variables que condicionan la formación de los desgastes por uso en dichas piezas. Los resultados traceológicos obtenidos del programa experimental y de un variado conjunto de dientes de hoz procedentes de distintos asentamientos arqueológicos del este de la península Ibérica han sido comparados. Entre otras conclusiones se puede señalar que los dientes de hoz fueron usados, preferentemente, como armaduras de hoces en labores de siega. La vida útil de los dientes de hoz en labores de siega es muy amplia, alcanzado varias jornadas de trabajo y, además, no fueron empleados como los trillos actuales, insertados en grandes tablas de madera.

Palabras clave: Dientes de hoz; Hoces; agricultura de cereales; Edad del Bronce; Arqueología experimental.

\section{[en] Sickle teeth, sickles and Bronze Age: The contribution of an experimental mowing program}

Abstract. Although the so-called sickle blades are well known in all their morphological, technological and functional aspects, it was considered necessary to develop a new experimental archaeology program in order to validate some of the hypothesis raised up until now and delve into the study of the variables that condition the formation of use-wear marks in those tools.

In this study, we have compared the traceological results obtained from the experimental program and from a varied set of sickle blades from different archaeological settlements in the eastern Iberian Peninsula. Among other conclusions it can be pointed out that these lithic pieces were used mainly attached to a handle in mowing activities. The lifespan of sickle blades in mowing is very long, up to several days of work. In addition, sickle teeth were not used as in current threshing sledges, inserted into large wooden boards.

Keywords: Sickle teeth; Sickle; Cereal Agriculture; Bronze Age; Experimental Archaeology.

Sumario: 1. Introducción. 2. Sobre dientes de hoz y hoces en el Sudeste y Levante de la península Ibérica. 3. Premisas e hipótesis en el programa experimental de siega con hoces. 4. El programa experimental: metodología y material. 5. Planteamiento y desarrollo de la experimentación. 5.1. La réplica de las hoces. 5.2. Las materias de contacto. Algunos comentarios sobre el cultivo y siega de los cereales. 5.3. El esparto y los elementos de trillo. 5.5. Metodología del análisis traceológico. 6. Bibliografía.

$1 \quad$ Este trabajo ha sido realizado en el marco del proyecto de investigación "Espacios sociales y espacios de frontera durante el Calcolítico y la Edad del Bronce en el Levante de la península ibérica” (HAR2016-76586-P), financiado por el Ministerio de Economía y Competitividad de España. Las actuaciones arqueológicas de 2015 y 2016 y el estudio radiométrico cuentan con la autorización de la Generalitat Valenciana. Agradecemos a Mauro S. Hernández Pérez, María Jesús de Pedro Michó, Bernat Martí Oliver y Amparo Barrachina Ibáñez las facilidades dadas para el estudio de las piezas documentadas en sus excavaciones. También a Francia Galiana Botella, Elisa Doménech Faus y toda su familia su colaboración en dicho programa experimental, y a María Pastor Quiles, la traducción al inglés del resumen.

2 Instituto Universitario de Investigación en Arqueología y Patrimonio Histórico -INAPH-. Universidad de Alicante. javier.jover@ua.es

3 G.I. Tarha. Universidad de Las Palmas de Gran Canaria amelia.rodriguez@ulpgc.es

4 Instituto Universitario de Investigación en Arqueología y Patrimonio Histórico -INAPH-. Universidad de Alicante. palmira.torregrosa@ua.es 
Cómo citar: Jover Maestre, F. J.; Rodríguez Rodríguez, A.; Torregrosa Giménez, P. (2019): Dientes de hoz, hoces y Edad del Bronce: la contribución de un programa experimental de siega. Complutum, 30(1): 131-154.

\section{Introducción}

En el estudio de las producciones líticas talladas de la Edad del Bronce se ha señalado repetidas veces la importancia de los denominados como dientes de hoz (Pla 1958; Fortea 1973) o elementos de hoz denticulados (Martí 1977). Estos soportes, también conocidos como hojas sierra, sierras de hoz, elementos denticulados o denticulados con lustre (Martínez y Afonso 2013), han sido registrados en numerosos asentamientos del periodo, pero también parecen estar presentes desde finales del Calcolítico en el ámbito de la península Ibérica (Clemente et al. 2014).

$\mathrm{Su}$ estudio tecnológico y tipológico ha sido ampliamente abordado, dado su elevado número y representatividad (De Pedro 1984; Juan 1985; Jover 1998; 2008; Gibaja 2003a; 2004; Martínez y Afonso 2013), mientras que los análisis traceológicos han evidenciado su prioritario empleo como armadura de hoces en labores de siega de cereales (Harrison y Meeks 1987; Gutiérrez 1993; Gibaja 1999; 2003a; 2004; Clemente y Gibaja 1998; Ollé y Vergès 1998; Clemente et al. 1999; Alonso 1999; Alonso et al. 2000; Carrión et al. 2004). No obstante, también ha sido planteado su posible uso a posteriori en el corte para separar los tallos de las espigas, o de sus raíces, inclusive para cortar otro tipo de vegetales no leñosos (Gibaja 2003b: 140-144; Gibaja 2003a:128). Por otra parte, el lustre de visu que ha servido tradicionalmente para identificarlos puede generarse con el trabajo de otras materias, como algunas de naturaleza mineral, aunque el análisis microscópico permite discriminar entre ambos grupos.

Si bien la función principal de estas piezas está aparentemente bien establecida, desde nuestro punto de vista, todavía sigue siendo necesario realizar análisis de un mayor número de piezas procedentes de contextos arqueológicos, así como implementar programas de arqueología experimental para resolver cuestiones vinculadas a su funcionamiento y a los procesos de trabajo a los que van ligados ( $\mathrm{Si}$ gaut 1991). Continuar con la siega experimental con hoces en distintos tipos de situaciones, realizar otros supuestos o comparar con instrumentos actuales, permitirá reconocer mejor las diversas formas en que pudieron manipularse y aproximarnos a la vida útil de este tipo de soportes.

Por ello, en este trabajo presentamos los resultados obtenidos del estudio traceológico de un lote de elementos procedentes de casi una decena de asentamientos de la Edad del Bronce del área levantina de la península Ibérica, que han sido contrastados igualmente mediante un programa de investigación experimental de siega con hoces desarrollado en este ámbito geográfico. En definitiva, nuestro interés es mejorar y ampliar las bases metodológicas y heurísticas, para poder formular nuevas hipótesis e inferencias sobre las sociedades de la Edad del Bronce en el Este de la península Ibérica.

\section{Sobre dientes de hoz y hoces en el Sudeste y Levante de la península Ibérica}

Desde muy temprano, las investigaciones sobre la Edad del Bronce en las tierras del Sudeste y Levante peninsular destacaron la presencia de soportes lascares dentados. Ya S. Moreno (1942 [1870]: 53) indicó la abundancia de sierras de sílex en el yacimiento de San Antón (Orihuela), al igual que posteriormente lo hicieran los hermanos Siret (1890:142-149) al referirse a El Argar. Desde el principio se consideró su posible función como armaduras de hoces (Colominas 1927: 39; Botella 1928), aunque no sin argumentos en sentido contrario (Furgús 1937: 36). Sin embargo, el hallazgo de una hoz y 6 armaduras en el Mas de Menente (Pericot y Ponsell 1928: 106) venía a refrendar la primera hipótesis (Fig.1). 

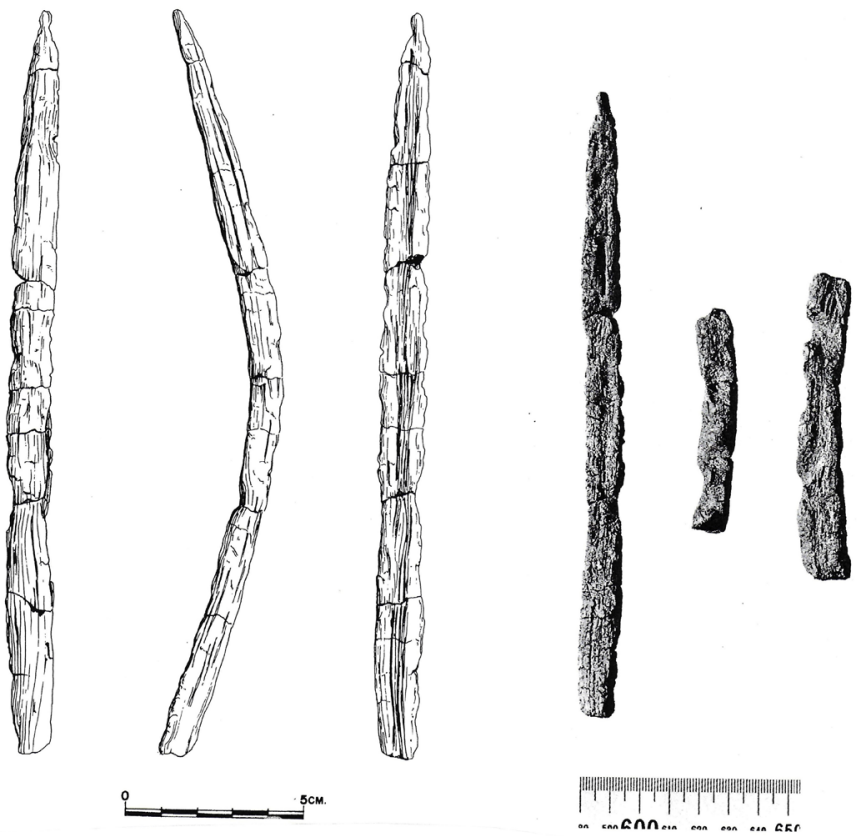

Figura 1. Dibujo y fotografía de los restos de la hoz documentada en el Mas de Menente (Alcoi, Alicante) (Juan 1985: 39, fig. 2; lám. 1).

Posteriormente, E. Cuadrado (1950: 105106), en su ensayo de tipología de los útiles y armas del territorio argárico, incluyó como características las hojas de sierra. Consideró que estaba probado su enmangue en hoces de madera, a veces pegadas con betún, y que el trillado de los cereales es posible que se realizase a mano o con otro procedimiento, pero no con trillos. Todo fue espléndidamente sintetizado por L. Monteagudo (1956) en el primer trabajo de síntesis sobre hoces prehistóricas.

Desde entonces se ha ido ponderando la importancia de estos elementos dentados dentro del elenco de útiles de la Edad del Bronce (Arnal et al. 1968; Tarradell 1963; Enguix 1975; Martí 1983; Juan 1985; 2009; Jover 1998; 2008, Gibaja 2003a; Martínez y Afonso 2013). Existe más de un centenar de yacimientos arqueológicos publicados con su registro (Siret y Siret 1890; Lull 1983; De Pedro 1984; Palomar 1995; Jover 1997; 1998; 2008; 2014; Gibaja 1999; 2002; 2003a; 2004; Martínez y Afonso 2013, entre otros). De ellos, cabe destacar la documentación de algunas concentraciones de varias piezas en contextos arqueológicos primarios que permiten inferir la presencia de posibles hoces in situ e incluso deducir su morfología. A las referencias del Mas de Menente (Ponsell 1926; Pericot y Ponsell 1928: 107), debemos añadir otros conjuntos.
Así, en la Sima del Ruidor en Teruel (Picazo 1991: 124) fueron registrados 19 elementos de hoz denticulados con lustre, aparecidos en un espacio reducido, interpretado como lugar de producción por la presencia de hogares. En los niveles antiguos de la ocupación argárica de Tabayá (Jover 1997) y sobre un suelo de ocupación fueron documentados los restos de una hoz con 9 piezas dispuestas de forma alineada en curva (Fig. 2). También se señalan datos similares para El Sambo -con 10 elementos- (Fig. 3), la Mola Alta de Serelles (Botella 1928), Muntanya Assolada (Juan 1985: 46), Ereta del Castellar (Arnal et al. 1968) o Cabezo Redondo (Hernández et al. 2016).

En resumen, la presencia de dientes de hoz agrupados -entre 9 y 19 , pero con mayor frecuencia en torno a 7-11-, asociados a posibles mangos de madera, y a veces conservando posiciones primarias sobre suelos de ocupación, ha sido una constante en las excavaciones efectuadas. La disposición de los elementos suele ser alineada creando un filo compuesto, y en algunos casos, describiendo una ligera curva. Estas agrupaciones podrían corresponder, o bien a hoces de distintos tamaños como es lógico suponer -aunque no se puede descartar la existencia de otro tipo de instrumentos-, o bien a la existencia en un mismo contexto cuando el número de elementos es más elevado de, al menos, dos hoces. 


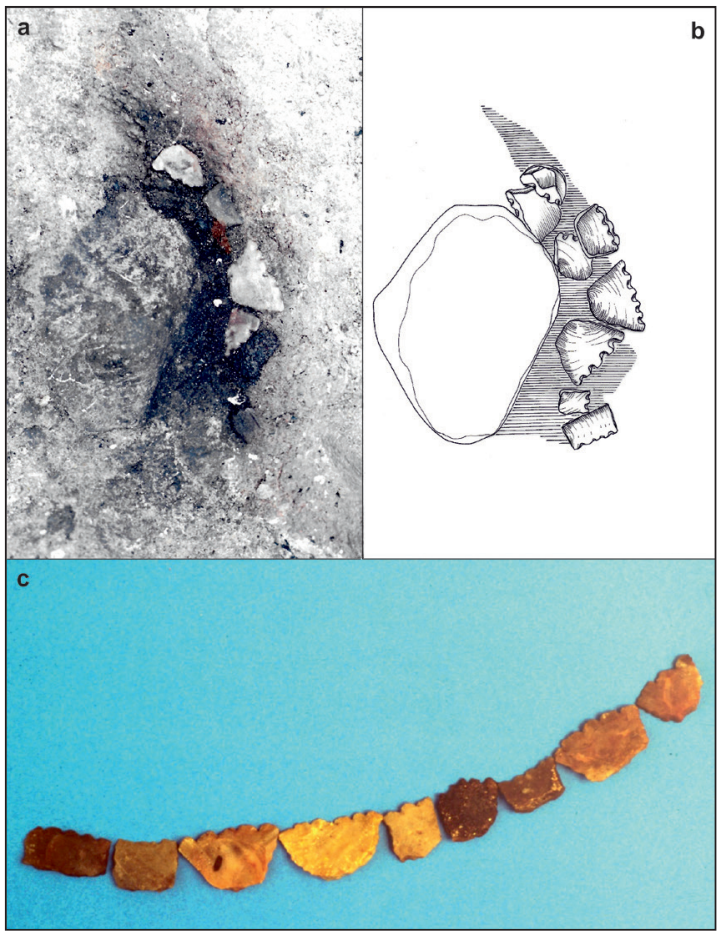

Figura 2. Hallazgo del conjunto de la hoz de Tabayá (Aspe, Alicante). Dibujo y montaje de la posible disposición original de los dientes de hoz en el montante de madera.

\section{Premisas e hipótesis en el programa experimental de siega con hoces}

El diente de hoz fue definido por J. Fortea (1973: 107) como "pieza corta generalmente sobre lámina, con extremidades preparadas bien por fractura simple, bien retocada, mostrando una denticulación muy regular en un borde, obtenida por muescas simples, directas inversas o bifaciales". Buena parte de las observaciones efectuadas con posterioridad (De Pedro 1984; Juan 1985; 2009; Jover 1997, 2008; 2014; Gibaja 1999; 2002, 2003a; Clemente et al. 1999) coinciden en señalar su estandarización tipométrica, morfológica y de modificaciones en los dorsos, con independencia de que los filos puedan estar o no retocados (Cuadrado 1950; Jover 1998; Gibaja 2003a; Martínez y Afonso 2013). En el filo, normalmente denticulado, es donde se localiza el típico lustre. Los estigmas asociados evidencian una cinemática longitudinal y una forma de aplicación de la fuerza mediante presión.

Aunque los estudios morfotécnicos y funcionales efectuados hasta la fecha han sugerido una serie de hipótesis sobre su posible funcionalidad, por nuestra parte consideramos necesario

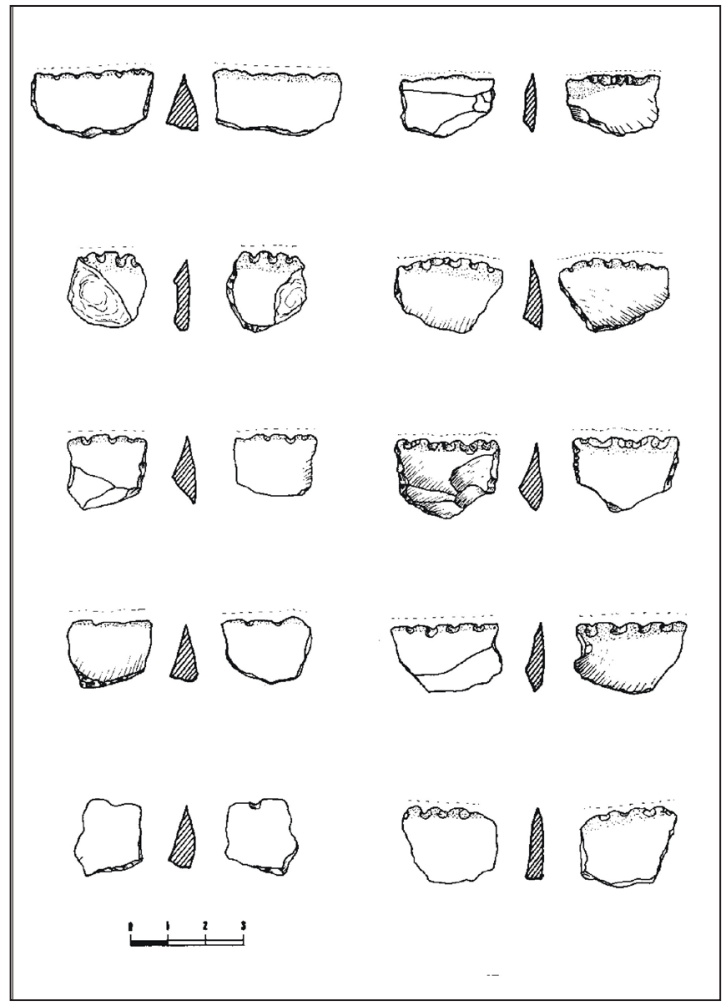

Figura 3. Conjunto de dientes de hoz asociados a una posible hoz documentada en El Sambo (Novelda, Alicante).

implementar un nuevo programa experimental. Con él se pretendía la validación de la hipótesis más plausible que viene a considerar que se trataría exclusivamente de armaduras de hoces para la siega de cereales, pero también de vegetales blandos, en cuyo caso se podrían deducir una serie de consecuencias referentes tanto a las características de su producción como a su efectividad laboral que pasamos a exponer:

a. La producción lítica tallada durante la Edad del Bronce, estaría orientada prioritariamente a la manufactura de este tipo de armaduras de hoces. No en vano, el trigo y la cebada son las principales especies documentadas en los contextos de la Edad del Bronce (Jover 1999; Gibaja 2003a; Pérez 2013), así como las áreas de molienda.

b. Las modificaciones de desbastado y retoque realizadas a dichas piezas constituyen un proceso más en su manufactura, tanto para acondicionarlos y fijarlos mejor en la hoz, como para mejorar la efectividad del borde activo. La aplicación de las muescas regulares que caracterizan a los dientes de hoz, debía constituir una acción técnica ne- 
cesaria para conseguir mayor efectividad en la siega. Esto podría explicar la presencia de elementos configurados, con y sin retoque, y con y sin huellas de uso.

c. Las hoces fabricadas debieron ser similares a la documentada en Mas de Menente (Juan 1985). Estarían constituidas por un soporte de madera ligeramente curvo, en cuyo cuerpo se dispondrían los elementos de sílex de forma paralela, formando sus bordes activos un filo continuo compuesto. La empuñadura supondría una prolongación del cuerpo, no diferenciable necesariamente. Por el momento, no contamos con evidencias de otro tipo de hoces para la Edad del Bronce en el ámbito peninsular, aunque sí se constatan en el Neolítico (Gibaja et al. 2010; Gibaja et al. 2012b).

d. El número de elementos enmangados en cada hoz pudo ser variable, según la longitud de arco del soporte, lo que a su vez obedece a la elaboración de hoces de diferentes tamaños, adaptadas seguramente a las capacidades de cada segador o segadora (Astruc et al. 2012). No obstante, son varios los ejemplos en los que las hoces, por término general, llevarían insertados entre 7 y 11 elementos, aunque su número podría oscilar en función de distintas variables -longitud de filo, tamaño de los dientes de hoz, etc-.

e. La altura de corte de los tallos dependería de muchos factores económicos y culturales, pero en términos de efectividad es más recomendable el trabajo casi a ras de suelo, mientras que sería casi inviable hacerlo al nivel de la espiga.

f. En comunidades agropecuarias con escaso desarrollo de las fuerzas productivas, el trillado se podría realizar mediante el pisado de bóvidos, o bien a través del batido directo de las mieses con una madera, no siendo necesario el empleo de trillos. No se puede descartar la presencia de instrumentos para efectuar un trillado o corte manual sobre el suelo, o simplemente para cortar tallos, como ha sido expuesto para algunos elementos analizados de El Oficio (Gibaja 2003a: 128). Ahora bien, en caso de determinar la posible existencia de trillos similares a los actuales (Anderson 1994;
Gibaja 2003b), tendríamos que considerar un mayor grado de organización laboral, relacionado con la necesidad de obtención de volúmenes de grano por encima de las necesidades objetivas reales.

\section{El programa experimental: metodología y material}

Los programas experimentales relacionados con las prácticas agrícolas tienen ya una gran tradición y se han aplicado en muchos contextos diferentes. Con ello se ha pretendido obtener resultados que permitan reconocer aquellos aspectos más directamente ligados a las características ambientales de cada lugar, la variabilidad de especies cultivadas o las diferencias culturales o cronológicas de cada contexto arqueológico analizado (Steenberg 1979; Korobkova 1981; 1992; Skakun 1992; 1993; Reynolds 1992; Anderson et al. 1991; Gibaja 1994; Ibáñez et al. 2014; Astruc et al. 2012; López-Rodríguez 2013). Esa variabilidad justifica el desarrollo de lo que aquí se presenta, ajustada a las peculiaridades del Levante de la península Ibérica, con unas características climatológicas dominadas por la aridez. Así, se han seguido las propuestas de J.E. González y J.J. Ibáñez (1994) y J. F. Gibaja (2003b), en lo que respecta a la definición de las variables independientes que han sido controladas.

En primer lugar, partiendo de la definición inicial de diente de hoz propuesta por J. Fortea (1973: 107), ha sido necesario aportar mayor precisión sobre las características tecnológicas y morfológicas de estos elementos, ya que existe una cierta variabilidad por ámbitos territoriales en la península Ibérica (Harrison y Meeks 1987; Palomo et al. 2012; Gibaja et al. 2004b). Así, las piezas constatadas en el Sudeste peninsular son muy semejantes a los que tenemos documentados en el ámbito valenciano, constatándose en ocasiones soportes sin el característico retoque denticulado (Gibaja 2003a). También se ha planteado la posibilidad de que algunos elementos dentados sean parte de trillos debido al gran desarrollo de los degastes de los filos, la alta densidad de los accidentes lineales y la presencia de pulidos con componentes de contacto con materia mineral (Gibaja 2003b; Gibaja et al. 2012a). En el caso de los elementos constatados en el Este de la península Ibérica, se trata de un producto manufacturado sobre diversos tipos de 
materias primas, en sílex de forma habitual y mayoritariamente sobre lascas, aún cuando también están representados los soportes laminares y testimonialmente las plaquetas tabulares (Jover 2008). Generalmente están modificados acortando y estandarizando sus dimensiones mediante fracturas simples por percusión o retoque abrupto. Siempre se conserva, al menos, uno de los bordes laterales en el caso de las láminas y uno de los bordes o el extremo distal en el de las lascas, modificándolo mediante presión directa al aplicarle una serie de muescas con diversa orientación, dispuestas de forma más o menos regular sobre el filo activo, con ángulos comprendidos entre 15 y 48 grados. Se consiguen así, soportes con un borde agudo y un retoque denticulado regular, a base de muescas simples -de tendencia abrupta- de diversa orientación y longitudes comprendidas entre 12 y $70 \mathrm{~mm}$, aunque más del $60 \%$ se suele situar en torno a los 20-27 mm (Jover 2008) (Ver Figs. 3 y 4).
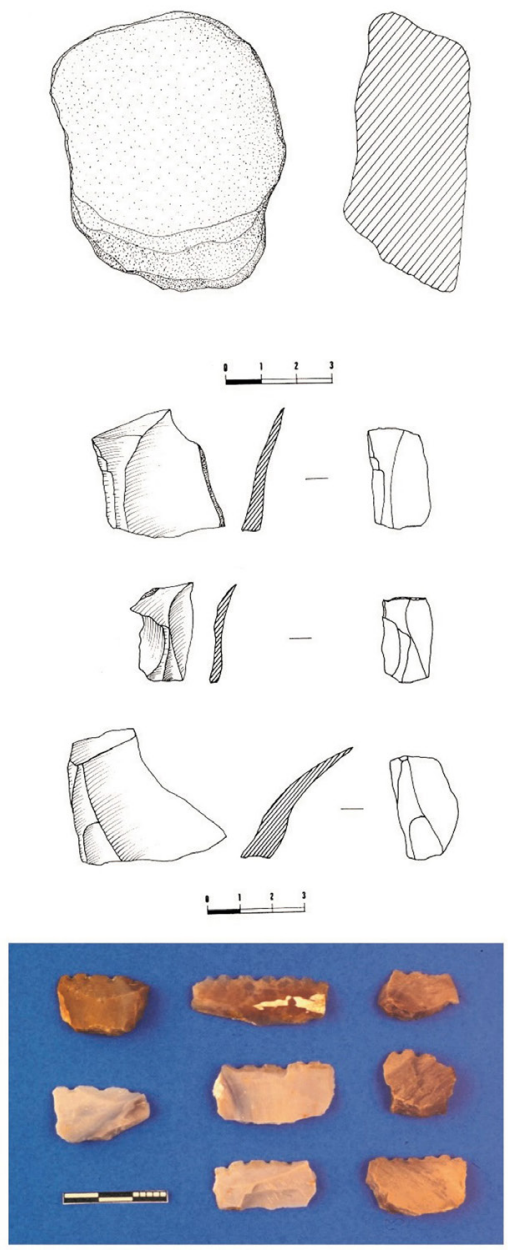

Figura 4. Material experimental. Nódulos de sílex, lascas en su proceso de configuración y dientes de hoz resultantes.
Aunque los elementos de hoz con el filo denticulado constituyen el grueso de los soportes retocados en los yacimientos de la Edad del Bronce, también se documentan piezas similares sin el filo modificado mediante retoque de delineación denticulada, a los que algunos investigadores han denominado como tabletas de hoz (Harrison y Meeks 1987), clasificándose, en ocasiones, incluso como geométricos. Algunos de estos cuentan con la característica de presentar igualmente el citado lustre por uso.

Junto a este tipo de piezas, en los asentamientos de la Edad del Bronce también se documentan otros tipos retocados como puntas de flecha, raspadores, lascas y láminas retocadas, pero siempre en porcentajes muy bajos. $\mathrm{Su}$ limitada presencia, ha hecho considerar que, algunos de ellos pudieron ser reclamos -piezas recuperadas de contextos arqueológicos- (Jover 1998; 2008; Martínez y Afonso 2013). No obstante, es evidente que los instrumentos tallados siguieron jugando un papel esencial en labores distintas a la recolección, como se ha puesto de manifiesto en los escasos estudios traceológicos emprendidos (Palomo et al. 2012).

En cualquier caso, el estudio de más de 3.000 dientes de hoz de numerosos asentamientos del Sudeste y Este peninsular (Jover 1997; 1998; 2008) permitió concretar los siguientes aspectos:

a. La morfología de la zona activa es lineal.

b. La forma de aplicación y la cinemática de la fuerza, teniendo en cuenta la distribución del lustre observado en todas ellas, el redondeado del bisel, la escasez de melladuras y la distribución de algunos accidentes lineales visibles macroscópicamente, se realiza mediante la presión con movimiento de trabajo paralelo al filo. Esto implica fundamentalmente corte o aserrado.

c. El ángulo del filo es de unos $15^{\circ}$ a $48^{\circ}$, es decir, filos agudos cortantes.

d. La presencia de lustre por uso, distribuido en ambas caras -aunque en muchos casos de manera asimétrica-, indica que el trabajo se realizó de forma perpendicular u oblicua -entre $90^{\circ}$ y $45^{\circ}$ -

e. La profundidad de las alteraciones por uso en algunos elementos llega a sobrepasar los $10 \mathrm{~mm}$ con respecto a la línea del filo, aunque lo más habitual suele ser $2-5 \mathrm{~mm}$. 


\section{Planteamiento y desarrollo de la experimentación}

\subsection{La réplica de las hoces}

El programa de réplica ha procurado atenerse a las variables independientes que singularizan el caso de los territorios que se incluyen en la tradicional área cultural del denominado como Bronce valenciano (Jover 1999). El sílex para confeccionar las piezas se recuperó, mediante un laboreo superficial, en el afloramiento de brechas y conglomerados del Plioceno conocido como Las Pedrizas (Villena, Alicante), fuente de abastecimiento destacada para los yacimientos de la cubeta de Villena (Molina 2016). A través del laboreo superficial se puede recolectar sílex de grano fino traslúcido, homogéneo, casi sin impurezas y sin líneas de fractura, de fácil talla; pero también bloques de grano medio, opaco y aspecto opaloide y sílex de grano grueso, de tacto áspero y amplia resistencia a la talla. Tradicionalmente, la población local ha empleado este sílex para la manufactura de los elementos de trillo.

Del conjunto de nódulos recogidos, seleccionamos un elevado número de bloques con los que se realizaron los procesos de talla experimental, intentando reflejar la variedad cualitativa presente en varios asentamientos del ámbito comarcal. Las dimensiones de los nódulos tallados no sobrepasaron los $90 \mathrm{~mm}$ de longitud y anchura. Fue considerado el tamaño del grano como forma de agrupar los sílex pudiendo establecerse tres agrupaciones, donde están representados principalmente los sílex de grano medio -3 variedades cromáticas-, grano fino y grano grueso.

Las labores de talla fueron realizadas mediante el empleo de la técnica de la percusión directa. Para ello, se contó con varios percutores duros y blandos, de diverso tamaño y peso, correspondientes a cantos de cuarcita, recogidos del mismo afloramiento de Las Pedrizas. También se utilizaron percutores blandos de asta de ciervo.

Las estrategias de talla seguidas trataron de reproducir las características de las lascas documentadas en el registro arqueológico -dimensiones, bulbos espesos y marcados, talones lisos y anchos, con ángulos inferiores a los $90^{\circ}$ - (Fig. 4). Se intentó la explotación siguiendo orientaciones unidireccionales y multidireccionales. Las modificaciones de las lascas con- sistieron en la eliminación, mediante percusión directa unipolar o bipolar, de los extremos de los soportes, especialmente, en la supresión de gran parte del extremo proximal o exclusivamente del talón. También en bastantes casos se modificó el borde opuesto al seleccionado como filo activo, con el objetivo de conformar el dorso. Este proceso se realizó mediante la percusión directa empleando percutores de cuarcita sobre un yunque. La necesidad de que encajaran mejor las piezas en la hoz fue el motivo que obligó a regularizar y reducir los dorsos o los lados cortos, mediante la aplicación de pequeños retoques abruptos profundos, bien directos, bifaciales o inversos.

En el filo activo también fueron aplicadas las muescas que caracterizan a la mayor parte de dientes de hoz, haciéndolo con posterioridad a la conformación del dorso y lados cortos, pero siempre previamente a su montaje en el mango de madera. Para la aplicación de las muescas se contó con punzones de hueso de punta roma sobre diáfisis de tibia de ovicaprino.

El número de muescas aplicadas en los filos se realizó en función de la longitud del mismo, guardando siempre una relación proporcional. Éstas fueron entre 3 y 5 normalmente, en su mayoría bifaciales, aunque también inversas y directas. El ángulo del filo también fue considerado, no solamente porque los dientes de hoz debían ser reproducidos lo más fielmente posible, sino debido a que es una de las variables independientes que era necesario controlar.

Los soportes de madera de pino carrasco que sirvieron como montantes fueron manufacturados de forma similar, con las mismas dimensiones y características, que la hoz documentada en Mas de Menente (Juan 1985) (Fig. 5). El resultado fue una empuñadura rectilínea, de cuerpo ligeramente curvo, sección de tendencia rectangular con las esquinas redondeadas, caras convexas y extremo distal ligeramente apuntado. Las medidas son de $39 \mathrm{~cm}$ de altura, $2,5 \mathrm{~cm}$ de anchura y $2 \mathrm{~cm}$ de grosor, pesando entre 150-160 gramos. La longitud de cuerda exterior de $44 \mathrm{~cm}$ e interior de $41,2 \mathrm{~cm}$. La longitud de cuerda del filo es de unos $21 \mathrm{~cm}$ y la longitud de la empuñadura de unos $11 \mathrm{~cm}$. En el arco interior fue creado un surco longitudinal y continuo para incrustar los elementos de hoz. Este surco presentaba una anchura variable entre 6 y $10 \mathrm{~mm}$ y una profundidad de unos 10-13 mm. 

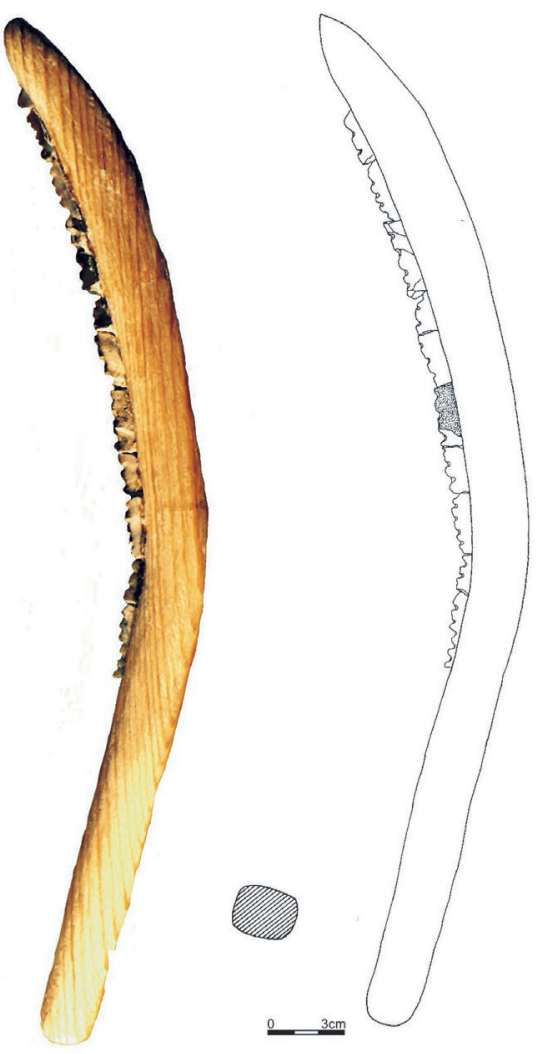

Figura 5. Hoz experimental similar a la del Mas de Menente.

Los elementos de hoz, una vez dentados, fueron montados en los surcos del cuerpo de las hoces de forma paralela, creando un filo continuo. El número de piezas que empleamos en su armado fue variado, debido a las diferencias de longitud de cada uno de los elementos. No obstante, éste fue establecido entre 8 y 10 piezas para cada hoz, teniendo como modelo las agrupaciones documentadas en contextos arqueológicos. Se combinaron soportes de $2^{\circ}$ y $3^{\circ}$ orden. En algún caso fue montado un soporte de $1^{\circ}$ orden. El ángulo de los filos osciló entre los $22^{\circ}$ y los $49^{\circ}$.

La resina de pino fue el material adherente y aglutinador que sirvió para mejorar la sujeción en el surco longitudinal. De este modo, se controló otra de las variables independientes como es la sujeción de las armaduras en un soporte de madera. El peso de las hoces una vez montadas fue de 205-215 gramos.

Al mismo tiempo, se intentó que los dientes de hoz manufacturados sobre distintos grupos de sílex y diferente calidad, estuviesen bien distribuidos, tanto en todas las hoces, como a lo largo del filo de cada una de ellas.

\subsection{Las materias de contacto. Algunos comentarios sobre el cultivo y siega de los cereales}

Es evidente que en la agricultura mediterránea el cultivo de los cereales ha sido, a lo largo de toda la Historia, la base económica subsistencial objetiva. Varios son los procesos de trabajo que tradicionalmente se han realizado en el ciclo agrícola cerealista, bien documentados en numerosos trabajos etnográficos (Escalera 1985; Korobkova 1992). Los cereales y en concreto, el trigo, exigen para su cultivo la existencia de una tierra limpia de vegetación, ya que la competencia con otras plantas repercute en la producción. Por ello, en toda tarea de preparación, como mínimo es necesario el desbroce del terreno y una labor de oxigenación de la tierra poco profunda para la que no se necesita el arado. Esta primera actuación era realizada normalmente a finales de verano, en el mes de agosto. La siguiente actividad es la siembra, que tradicionalmente en tierras del Levante de la península Ibérica se realiza entre finales de octubre y principios de noviembre. Después, era necesario escardar los trigales en febrero o principios de marzo, momento en el que las plantas alcanzan una altura de un palmo, evitando así la competencia con la vegetación parásita. Aunque se podía segar una parte para forraje entre los meses de febrero-junio, la siega para el consumo humano se realizaba en julio, cuando los trigales ya estaban sazonados.

Por nuestra parte, hemos intentado seguir los procesos de trabajo señalados, controlando además, algunos factores que inciden de forma directa en el desarrollo de las gramíneas. En primer lugar, consideramos que la zona donde debía ser sembrado el trigo-Triticum aestivum - tenía que disponer de unas características de humedad y pluviosidad medias dentro del territorio en estudio y ubicadas en lugares próximos a asentamientos donde se hubiesen documentado dientes de hoz.

El lugar elegido fue el Mas de la Cova (Cocentaina, Alicante) (Fig. 6), paraje situado en las estribaciones nororientales de la sierra de Mariola, a unos 700 m s.n.m., entre los yacimientos de la Edad del Bronce de Mastec y Mola Alta de Serelles. Las condiciones climatológicas en este lugar pueden ser extrapolables a gran parte del Prebético Meridional valenciano. Esta zona dispone de una temperatura media anual de $15,6^{\circ}$, con máximas 


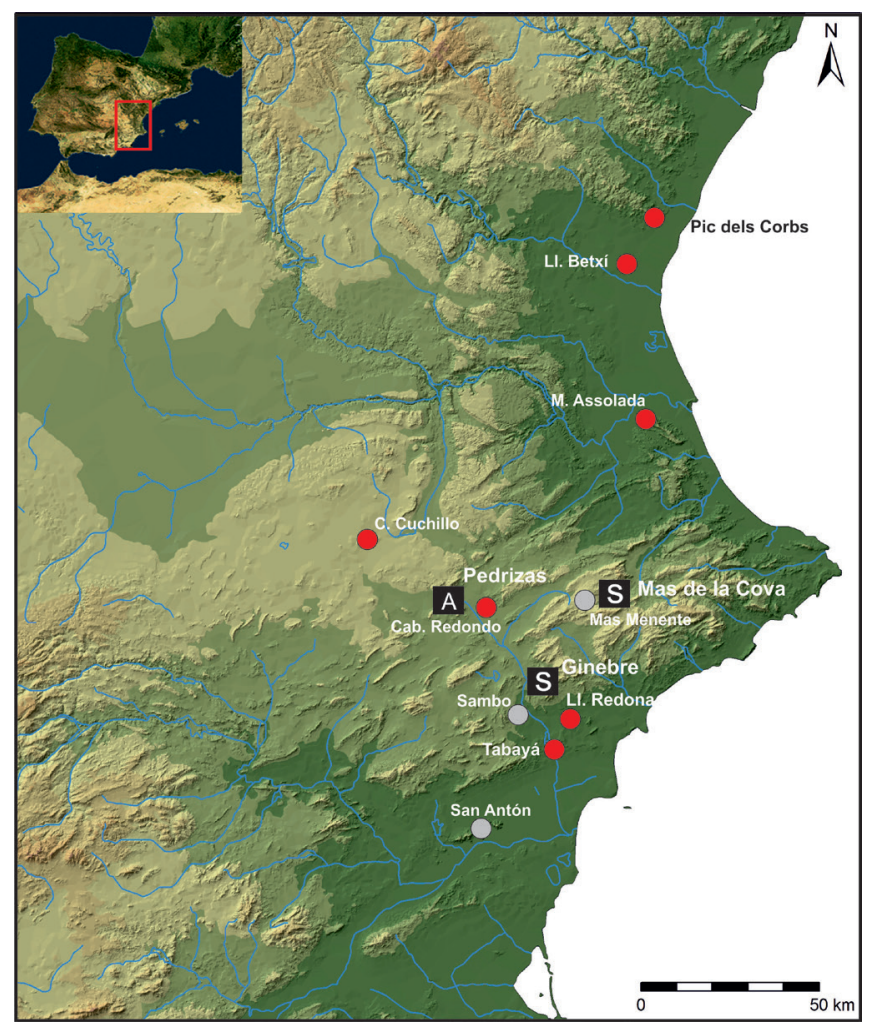

Figura 6. Mapa de distribución de los yacimientos de los que han sido estudiados dientes de hoz (círculos en rojo) e indicación de otros citados (en gris). También se señala con un cuadrado los lugares donde se efectuaron las labores de siega de cereales (Mas de la Cova), de siega de esparto (Ginebre, Petrer) y procedencia de los bloques de sílex seleccionados para elaborar los dientes de hoz experimentales (Las Pedrizas, Villena).

del mes más frío de $13,1^{\circ}$ y mínimas de $3^{\circ}$. El número de días libres de heladas es de 230 y las precipitaciones medias anuales son de 479 $\mathrm{mm}$, algo más elevadas que las existentes en el sureste peninsular en la actualidad. En la zona donde fue sembrado el trigo, se podían observar algunas concentraciones de pino carrasco y carrasca. La zona elegida para la siembra fue una pequeña vaguada con tierras de baja calidad por la presencia de margas triásicas. $\mathrm{La}$ zona sembrada constituyó cerca de $1.000 \mathrm{~m}^{2}$, debidamente limpiada con azadones a finales de agosto.

A principios de noviembre se procedió a la siembra, esparciendo el grano a voleo, pasando luego unas ramas de gran tamaño para enterrar el grano. Los campos sembrados no fueron escardados con el objeto de evaluar el desarrollo de otras vegetaciones parásitas. El resultado fue el brote en determinados lugares de cardos y amapolas que, previamente a la siega del trigo, fueron eliminados. Así, una vez desarrollado el trigal, éste presentaba una densidad bastante aceptable, con plantas entre 50 y $80 \mathrm{~cm}$ de altura, aunque mayoritariamente en torno a los $65 \mathrm{~cm}$.

Las labores de siega empleando las hoces de madera fueron realizadas en dos veranos consecutivos, llevándose a cabo a inicios del mes de julio (Fig. 7a y b). El trigo se encontraba ya sazonado, bastante maduro y la tierra bastante seca, sin polvo. En el proceso de siega fueron utilizadas varias hoces con el objetivo de controlar las otras dos variables independientes restantes. Por un lado, el tiempo de uso. En este caso todas las hoces se usaron un mínimo de 50 minutos. El máximo fue de 12 horas para algunas de ellas. La otra variable fue el número de acciones. Este número oscilaba considerablemente en función de la experiencia de la persona que la llevara a cabo (Astruc et al. 2012) y del tiempo de trabajo. El máximo de acciones en los primeros $50 \mathrm{mi}$ nutos fue de 1.120, mientras que el mínimo se situó en las 720. A las 2 horas de trabajo se habían alcanzado las 1.690, mientras que a las 
4 horas se había conseguido las 4.353 acciones por parte de segadores expertos.

Para la realización de la siega se contó en todo el proceso con las enseñanzas de un experto segador, D. José Doménech. Las hoces fueron manejadas en los procesos de siega por diversas manos, aunque siguiendo los mismos principios de uso aprendidos. Estos consistieron en sujetar con una mano un manojo de tallos de trigo a una altura media-baja, mientras con la otra mano se sostenía la hoz (Fig. 7c y d). En una acción simultánea, mientras la mano que agarraba el manojo realizaba un mo- vimiento en dirección opuesta al cuerpo, intentado doblar las mieses, la mano que sujetaba la hoz dispuesta con el filo activo frente al segador, debía realizar la acción contraria, un movimiento del brazo tirando con dirección hacia el cuerpo y cortando los tallos a unos $6-10 \mathrm{~cm}$ del suelo. La superficie de trigal segada en distintas anualidades fue de unos $827 \mathrm{~m}^{2}$. Una vez que finalizó el trabajo, las hoces fueron debidamente guardadas y protegidas para que los filos no sufrieran ningún tipo de alteraciones en su desplazamiento hasta el laboratorio para su análisis.

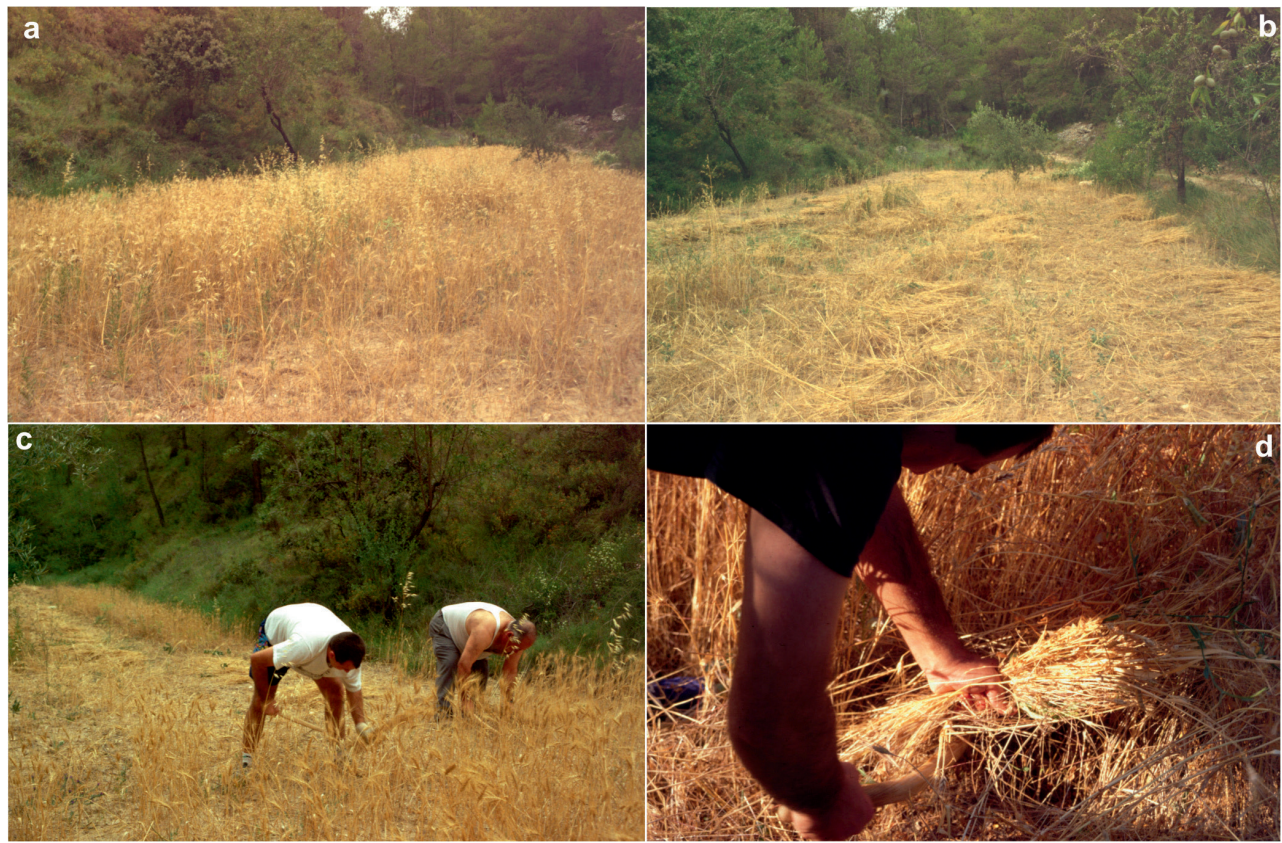

Figura 7. Imágenes del campo de cultivo situado en el Mas de la Cova (Cocentaina, Alicante) antes y después de la siega, así como dos momentos del proceso de siega efectuado.

\subsection{El esparto y los elementos de trillo}

Por otro lado, también consideramos necesario llevar a cabo labores de siega de esparto, aunque de forma tradicional es arrancado a mano. Dicho proceso fue realizado de igual modo que las gramíneas, controlando los tiempos de uso y el número de acciones. Las matas de esparto segadas fueron las existentes en el piedemonte de los Puntales del Ginebre (Petrer, Alicante) (ver Fig. 6), muy próximas al asentamiento del mismo nombre, aunque en una zona con una pluviosidad algo más escasa que la zona de cereales segada $-300 \mathrm{~mm}$ anuales-.

Se trata de grandes matas de atocha constituidas, tanto por tallos verdes en las zonas in- teriores, como secas en la periferia, mostrando mayor resistencia las primeras. El tiempo dedicado a esta labor fue de 50 y 120 minutos, ya que el uso de hoces se mostró como muy poco efectivo. Para la realización de dicha labor se contó con la colaboración de D. José Jover Pastor, segador durante años.

Después de realizar el estudio traceológico de todos los dientes de hoz, fueron seleccionadas diversas piezas con 4 y 2 horas y 50 minutos de uso para ser engarzados nuevamente en tres hoces y continuar las labores de siega al año siguiente. Se llegó a alcanzar en algunas piezas las 12 horas de trabajo.

Además del material experimental reseñado, se incluyeron en el análisis traceológico dos ele- 
mentos de sílex procedentes de trillos empleados a mediados del siglo XX (Fig. 8). Se trataba de 2 lascas de sílex de grano medio y pequeño tamaño, con talón liso y bulbo destacado, extraídas de dos trillos. Estos soportes se obtuvieron mediante percusión directa. Ambos presentan en el filo activo una pátina por uso, dispuesta de forma longitudinal en ambas caras conocida como "lustre". La profundidad del lustre alcanza en ambos casos entre los 5 y $7 \mathrm{~mm}$.
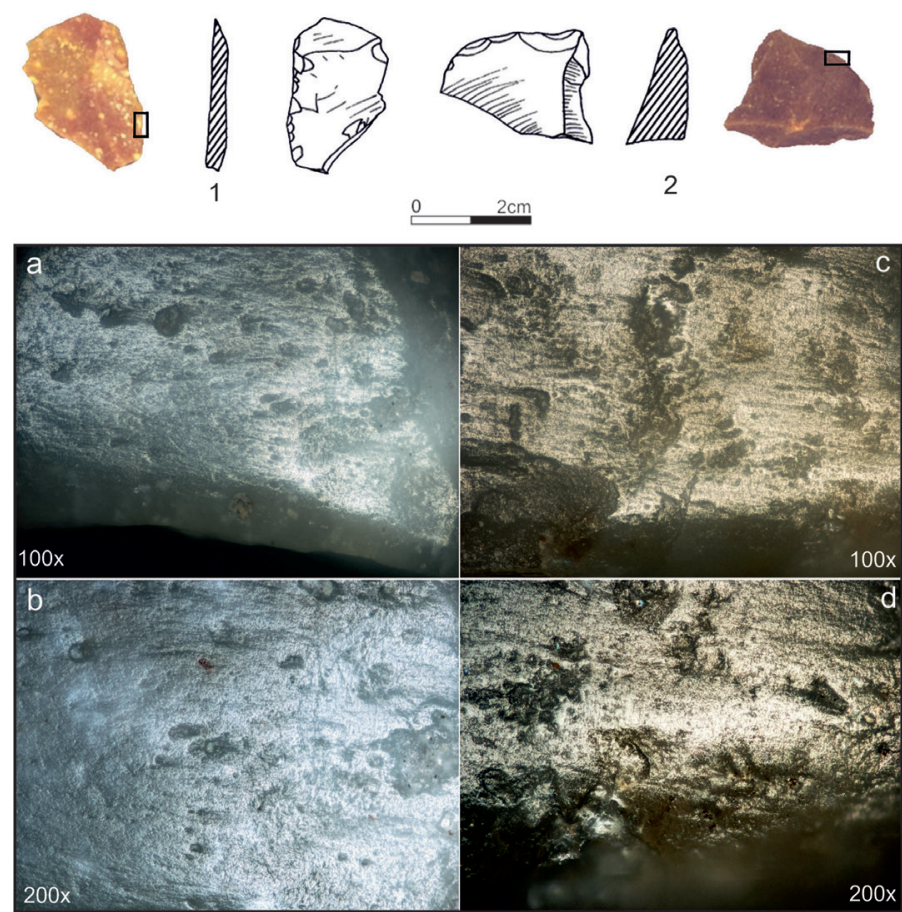

Figura 8. Elementos de trillo analizados. Detalle de las huellas de uso a diferentes aumentos (a y b pieza 1; c y d pieza 2).

\subsection{EI material arqueológico}

Junto al programa experimental también fueron analizados un total de 54 dientes de hoz procedentes de 7 asentamientos de la Edad del Bronce excavados en las últimas décadas en el área del Levante peninsular (ver Fig. 6). Se trata de núcleos de hábitat, tanto argáricos como del Bronce Valenciano y del área de La Mancha oriental, en los que se han aplicado sistemas de registro arqueológico exhaustivos, que han permitido reconocer contextos con distinta calidad de información. Así, las piezas proceden, por un lado, de dos agrupaciones -9 dientes de hoz dispuestos formando un filo continuo sobre un suelo de ocupación de Tabayá (ver Fig. 2) (Hernández y López 2010) y 15 del Cerro de El Cuchillo (Hernández et al. 1994)- y, por otro, de elementos aislados en unidades de derrumbe o secundarias de otros enclaves -Pic dels Corbs (Barrachina 2012),
Lloma de Betxí (De Pedro 1998), Muntanya Assolada (Martí 1983), Lloma Redona (Navarro 1986) y Cabezo Redondo (Hernández et al. 2016)-.

Se trata de asentamientos ubicados en la cima y laderas de cerros, con la excepción de Tabayá, sito en una elevada estribación montañosa. Las actuaciones arqueológicas efectuadas han permitido determinar la presencia en todos ellos de unidades habitacionales de diferente tamaño, incluso, en algún caso como Cabezo Redondo, la agrupación de unidades comunicadas a través de calles o pasillos. El tamaño o extensión superficial de los mismos también difiere considerablemente, ya que mientras la Lloma Redona fue un núcleo inferior a los 0,04 Ha, Cabezo Redondo pudo superar la hectárea. De igual modo, han sido constatadas claras diferencias en cuanto a prácticas sociales y materialidad, en relación con su pertenencia a distintos gru- 
pos culturales así como la secuencia de ocupación y el espectro cronológico de cada uno de ellos.

\subsection{Metodología del análisis traceológico}

El análisis se desarrolló en el Laboratorio de Arqueología de la Universidad de Las Palmas de Gran Canaria. Se realizó una inspección de visu para determinar la distribución de los restos de sustancias vegetales en el filo y de resina en el cuerpo, disponiendo previamente de los dibujos a escala real. Después se procedió a su limpieza con agua y jabón en una cubeta de ultrasonidos, aunque algunos residuos siguieron adheridos a las superficies. El material fue observado mediante una lupa binocular Nikon SMZ 1000 dotada con un rango de aumentos de $8 \mathrm{X}$ a $80 \mathrm{X}$, y un microscopio metalográfico Nikon Labophot 2 con un rango de aumentos de 50X a 400X. La fotografía se realizó con una cámara Nikon SD-Fil. En algunos casos se realizó una compilación de fotografías mediante el programa Helicon Focus. Se prestó atención a la distribución y características de las huellas en los distintos niveles de observación, desde los 8 a los 400 aumentos. La identificación, ubicación y descripción de los estigmas se ha consignado en una base de datos. Según la metodología estándar ampliamente descrita en la bibliografía (González e Ibáñez 1994).

\section{Resultados y discusión}

Los resultados derivados de la observación del material del programa experimental, de los elementos procedentes de contextos arqueológicos y de los dos elementos de trillo de época contemporánea muestran algunas diferencias relevantes que merecen ser descritas de forma detenida.

En primer lugar, los estigmas identificados en los elementos de trillo se caracterizan por presentar un desgaste bastante significativo del filo activo (Tabla 1; Fig. 8). Consiste en una pérdida de volumen debido a un considerable astillado, con melladuras de diferentes tamaños, pero también a un destacado redondeado del filo y las aristas adyacentes, que a su vez muestran un lustre brillante e intenso por ambas caras. El pulido que acompaña la zona redondeada del bisel ha penetrado más de $10 \mathrm{~mm}$. Se caracteriza por su trama cerrada, que mezcla zonas brillantes y mates. Tiene un aspecto rugoso, en el que se observan microcráteres y abundantes estrías, muchas colmatadas, por lo que unas son anchas e irregulares con fondo oscuro y otras más estrechas y brillantes. El aspecto final es bombeado y son muy discretas las formas onduladas que evocan el contacto con una materia vegetal más rica en humedad. Estas características lo diferencian de los estigmas documentados en las experimentales de siega y arqueológicas, en general.

Tabla 1. Principales rasgos descriptivos de las piezas analizadas según su uso y tiempo de trabajo en minutos $(\mathrm{m})$.

\begin{tabular}{|c|c|c|c|c|c|}
\hline & $\begin{array}{c}\text { De visu y lupa } \\
\text { binocular a } \\
\text { Bajos aumentos }\end{array}$ & $\begin{array}{c}\text { Microscopio } \\
\text { Trama }\end{array}$ & $\begin{array}{c}\text { Microscopio } \\
\text { Penetración a } \\
100 X\end{array}$ & $\begin{array}{c}\text { Microscopio } \\
\text { Estrías }\end{array}$ & $\begin{array}{c}\text { Microscopio } \\
\text { Pulidos }\end{array}$ \\
\hline $\begin{array}{l}\text { Elementos } \\
\text { de trillo }\end{array}$ & $\begin{array}{l}\text { Desgaste conside- } \\
\text { rable. Astillado con } \\
\text { melladuras pulidas. }\end{array}$ & $\begin{array}{l}\text { Muy cerrada, } \\
\text { brillante pero mate, } \\
\text { de aspecto rugoso, } \\
\text { ondulado con vo- } \\
\text { lumen. }\end{array}$ & $\begin{array}{l}\text { Muy cerrada casi } \\
1 \mathrm{~cm} .\end{array}$ & $\begin{array}{l}\text { Superficie pulida } \\
\text { surcada por nume- } \\
\text { rosas estrías col- } \\
\text { matadas que parten } \\
\text { de microcráteres } \\
\text { y cubren toda la } \\
\text { superficie. }\end{array}$ & $\begin{array}{l}\text { Pulido intenso muy } \\
\text { transformado por } \\
\text { estrías y melladuras } \\
\text { pulidas. }\end{array}$ \\
\hline $\begin{array}{l}\text { Siega } \\
\text { Esparto } \\
50 \mathrm{~m}\end{array}$ & $\begin{array}{l}\text { Desgaste inexisten- } \\
\text { te o no se observa. }\end{array}$ & $\begin{array}{l}\text { Melladuras bifacia- } \\
\text { les abundantes de } \\
\text { terminación afinada } \\
\text { o en media luna. }\end{array}$ & 100 micras & $\begin{array}{l}\text { Escasas o inexis- } \\
\text { tentes. }\end{array}$ & $\begin{array}{l}\text { Marginal de dis- } \\
\text { tribución lineal, } \\
\text { irregular sin aspecto } \\
\text { abrasivo. } 10 \text { micras } \\
\text { de penetración. }\end{array}$ \\
\hline
\end{tabular}




\begin{tabular}{|c|c|c|c|c|c|}
\hline & $\begin{array}{c}\text { De visu y lupa } \\
\text { binocular a } \\
\text { Bajos aumentos }\end{array}$ & $\begin{array}{c}\text { Microscopio } \\
\text { Trama }\end{array}$ & $\begin{array}{l}\text { Microscopio } \\
\text { Penetración a } \\
\text { 100X }\end{array}$ & $\begin{array}{l}\text { Microscopio } \\
\text { Estrías }\end{array}$ & $\begin{array}{l}\text { Microscopio } \\
\text { Pulidos }\end{array}$ \\
\hline $\begin{array}{l}\text { Siega } \\
\text { esparto } \\
120 \mathrm{~m}\end{array}$ & $\begin{array}{l}\text { Desgaste mínimo } \\
\text { con ligero brillo en } \\
\text { las partes salientes } \\
\text { de los dientes. }\end{array}$ & $\begin{array}{l}\text { Continua. Cerrada } \\
\text { en el mismo bisel, } \\
\text { brillante, bien arti- } \\
\text { culada y de aspecto } \\
\text { plano. } \\
\text { Melladuras aisla- } \\
\text { das, unifaciales o } \\
\text { bifaciales, de termi- } \\
\text { nación reflejada. }\end{array}$ & $600-1000$ micras & Escasas & $\begin{array}{l}\text { Pulido continuo en } \\
\text { el bisel. }\end{array}$ \\
\hline $\begin{array}{l}\text { Siega } \\
\text { cereales } \\
50 \mathrm{~m}\end{array}$ & No se observa. & $\begin{array}{l}\text { Media en las in- } \\
\text { mediaciones del } \\
\text { bisel que se abren } \\
\text { rápidamente. Poco } \\
\text { articuladas. }\end{array}$ & $\begin{array}{l}\text { Media puntual y } \\
\text { abierta entre } 100 \mathrm{y} \\
600 \text { micras. }\end{array}$ & $\begin{array}{l}\text { Aristas visibles en } \\
\text { el retoque de las } \\
\text { muescas a veces } \\
\text { formando haces. } \\
\text { Cortas y de fondo } \\
\text { oscuro unas y lar- } \\
\text { gas, finas y brillan- } \\
\text { tes otras. }\end{array}$ & $\begin{array}{l}\text { Discontinuos de } \\
\text { distribución irre- } \\
\text { gular en las partes } \\
\text { salientes. }\end{array}$ \\
\hline $\begin{array}{l}\text { Siega } \\
\text { cereales } \\
120 \mathrm{~m}\end{array}$ & $\begin{array}{l}\text { Ligero pulido en } \\
\text { sílex de grano fino. }\end{array}$ & $\begin{array}{l}\text { Media en el bisel, } \\
\text { pero articulada. }\end{array}$ & $\begin{array}{l}\text { Trama media hasta } \\
700 \text { micras. }\end{array}$ & $\begin{array}{l}\text { Estrías escasas } \\
\text { agrupadas en ha- } \\
\text { ces, de densidad } \\
\text { variada, cortas y de } \\
\text { fondo oscuro mayo- } \\
\text { ritariamente. }\end{array}$ & $\begin{array}{l}\text { Distribución irre- } \\
\text { gular sin invadir las } \\
\text { depresiones de las } \\
\text { muescas. De brillo } \\
\text { moderado y escaso } \\
\text { volumen con micro- } \\
\text { cráteres. }\end{array}$ \\
\hline $\begin{array}{l}\text { Siega } \\
\text { cereales } \\
240 \mathrm{~m}\end{array}$ & $\begin{array}{l}\text { Ligero pulido toda- } \\
\text { vía no observable } \\
\text { en sílex de grano } \\
\text { grueso. }\end{array}$ & $\begin{array}{l}\text { Cerrada en algunos } \\
\text { segmentos del bisel, } \\
\text { pero con predo- } \\
\text { minio de la trama } \\
\text { media con buen } \\
\text { reticulado. }\end{array}$ & $\begin{array}{l}\text { Trama media hasta } \\
1 \mathrm{~mm} .\end{array}$ & $\begin{array}{l}\text { Numerosas estrías } \\
\text { agrupadas en haces, } \\
\text { cortas y de fondo } \\
\text { oscuro. }\end{array}$ & $\begin{array}{l}\text { Continuo, de dis- } \\
\text { tribución irregular. } \\
\text { Más desarrollado en } \\
\text { las caras ventrales. }\end{array}$ \\
\hline $\begin{array}{l}\text { Siega } \\
\text { cereales } \\
\mathbf{3 6 0 ~ m}\end{array}$ & $\begin{array}{l}\text { Desgaste visible } \\
\text { en algunos puntos } \\
\text { del bisel con me- } \\
\text { lladuras en media } \\
\text { luna en los filos } \\
\text { retocados. }\end{array}$ & $\begin{array}{l}\text { Cerrada en el bisel } \\
\text { en torno y en algu- } \\
\text { nas aristas de las } \\
\text { muescas. }\end{array}$ & $\begin{array}{l}\text { Cerrada por debajo } \\
\text { de } 1000 \text { micras. } \\
\text { Media hasta casi } \\
2 \mathrm{~mm} .\end{array}$ & $\begin{array}{l}\text { Estrías abundantes, } \\
\text { agrupadas en haces, } \\
\text { confiriendo un } \\
\text { aspecto erosivo. }\end{array}$ & $\begin{array}{l}\text { Pulido continuo, de } \\
\text { penetración irregu- } \\
\text { lar. Reflectante, con } \\
\text { volumen y buen } \\
\text { reticulado. }\end{array}$ \\
\hline $\begin{array}{l}\text { Siega } \\
\text { cereales } \\
480 \mathrm{~m}\end{array}$ & $\begin{array}{l}\text { Ligero reflejo de la } \\
\text { zona pulida a sim- } \\
\text { ple vista en sílex } \\
\text { fino. }\end{array}$ & $\begin{array}{l}\text { Cerrada en el bisel } \\
\text { y aristas de las } \\
\text { muescas. }\end{array}$ & $\begin{array}{l}\text { Cerrada en deter- } \\
\text { minados segmentos } \\
\text { hasta } 3 \mathrm{~mm} \text {. Media } \\
\text { y abierta hasta más } \\
\text { allá de } 5 \mathrm{~mm} \text {. }\end{array}$ & $\begin{array}{l}\text { Estrías abundantes, } \\
\text { donde se combinan } \\
\text { cortas de fondo } \\
\text { oscuro con largas } \\
\text { y brillantes. Cierto } \\
\text { aspecto erosivo. }\end{array}$ & $\begin{array}{l}\text { Pulido continuo de } \\
\text { penetración más re- } \\
\text { gular. Con volumen } \\
\text { y buen reticulado. }\end{array}$ \\
\hline $\begin{array}{l}\text { Siega } \\
\text { cereales } \\
720 \mathrm{~m}\end{array}$ & $\begin{array}{l}\text { Ligero reflejo de la } \\
\text { zona pulida, excep- } \\
\text { to en algunas piezas } \\
\text { de grano grueso. }\end{array}$ & $\begin{array}{l}\text { Trama cerrada en el } \\
\text { bisel, mejor arti- } \\
\text { culada. }\end{array}$ & $\begin{array}{l}\text { Cerrada hasta } 4 \mathrm{~mm} \\
\text { y media y abierta } \\
\text { hasta } 9 \mathrm{~mm} .\end{array}$ & $\begin{array}{l}\text { Estrías abundantes } \\
\text { con dominio de } \\
\text { las cortas de fondo } \\
\text { oscuro. }\end{array}$ & $\begin{array}{l}\text { Pulido continuo con } \\
\text { penetración regular. } \\
\text { Con volumen y } \\
\text { buen reticulado. }\end{array}$ \\
\hline $\begin{array}{l}\text { Grupo } \\
\text { 3. Piezas } \\
\text { arqueoló- } \\
\text { gicas }\end{array}$ & $\begin{array}{l}\text { Desgaste moderado } \\
\text { en ambas caras del } \\
\text { filo. Reflejo acu- } \\
\text { sado de las zonas } \\
\text { pulidas. }\end{array}$ & $\begin{array}{l}\text { Cerrada. Redondea- } \\
\text { do del bisel. }\end{array}$ & $\begin{array}{l}\text { Superior a } 100 \\
\text { micras. }\end{array}$ & $\begin{array}{l}\text { Estrías de fondo } \\
\text { oscuro dispuestas } \\
\text { de forma paralela al } \\
\text { filo, con presencia } \\
\text { de microcráteres } \\
\text { abrasivos. }\end{array}$ & $\begin{array}{l}\text { Pulido brillante, } \\
\text { voluminoso y de } \\
\text { aspecto líquido. }\end{array}$ \\
\hline
\end{tabular}




\begin{tabular}{|c|c|c|c|c|c|}
\hline & $\begin{array}{c}\text { De visu y lupa } \\
\text { binocular a } \\
\text { Bajos aumentos }\end{array}$ & $\begin{array}{c}\text { Microscopio } \\
\text { Trama }\end{array}$ & $\begin{array}{c}\text { Microscopio } \\
\text { Penetración a } \\
\text { 100X }\end{array}$ & $\begin{array}{c}\text { Microscopio } \\
\text { Estrías }\end{array}$ & $\begin{array}{c}\text { Microscopio } \\
\text { Pulidos }\end{array}$ \\
\hline $\begin{array}{l}\text { Grupo } \\
\text { 4. Piezas } \\
\text { arqueoló- } \\
\text { gicas }\end{array}$ & $\begin{array}{l}\text { Desgaste acusado } \\
\text { del bisel con bisel } \\
\text { redondeado y em- } \\
\text { botado. }\end{array}$ & $\begin{array}{l}\text { Muy cerrada y } \\
\text { profunda localizada } \\
\text { en ambas caras del } \\
\text { filo. }\end{array}$ & $\begin{array}{l}\text { Penetra en muchos } \\
\text { entre } 3 \text { y } 4 \mathrm{~mm} \text { y } \\
\text { en algunos hasta } \\
11 \mathrm{~mm} .\end{array}$ & $\begin{array}{l}\text { Superficie pulida } \\
\text { surcada de estrías } \\
\text { colmatadas, de } \\
\text { aspecto abrasivo, } \\
\text { o bien de fondo } \\
\text { oscuro, o bien con } \\
\text { sucesión de micro- } \\
\text { cráteres. }\end{array}$ & $\begin{array}{l}\text { Pulido continuo, } \\
\text { muy profundo, } \\
\text { brillante, de aspecto } \\
\text { liso y líquido. }\end{array}$ \\
\hline
\end{tabular}

Por lo que respecta a las huellas de uso documentadas tras la experimentación de la siega de trigo, aunque se detecta un patrón recurrente, los estigmas pueden variar su desarrollo en función del tiempo de uso, la disposición de los dientes en la hoz y la granulometría del sílex.

En las piezas usadas durante 50 minutos la presencia y densidad de las melladuras es muy variable y depende del ángulo del filo activo y de la granulometría del sílex, siendo los más finos los más afectados por estas descamaciones (Fig. 10). En consecuencia, en los sílex de grano grueso se detectan melladuras aisladas, mientras que en los finos pueden aumentar su densidad y presentarse mayoritariamente en un único lado o ser bifaciales. El desgaste del filo solo es observable al microscopio a partir de 100X. Está muy restringido al bisel y a veces es discontinuo. Nuevamente, las trazas de utilización se forman más rápidamente en las microtopografías más regulares, es decir, en aquéllas de grano más fino.

Los accidentes lineales tampoco se han detectado en todas las piezas experimentales. Sin embargo, pueden observarse componentes lineales en el pulido que no dejan lugar a dudas sobre la cinemática del útil. En las microtopografías más regulares sí que se detectan estrías. Éstas son bifaciales, aunque en algunos casos su densidad es desigual, siendo más abundantes en la cara de la pieza que estaba más cerca del suelo. Estos accidentes lineales tienen una distribución longitudinal en el filo, siendo más evidentes sobre las aristas conformadas por el retoque de las muescas, donde pueden unirse en haces. En general, son cortas y de fondo oscuro, aunque en algunos dientes también las hay más largas, finas y brillantes, como de choque con una materia más dura. Por último, existen unas pocas estrías colmatadas de pulido.

El pulido tiene una distribución discontinua e irregular, siendo marginal y como pasa- ba con la densidad de las estrías, puede que su penetración sea diferente en sus dos caras. Así, a 100X penetra entre 100 y 600 micras sobre el mismo filo. El pulido tiene una trama media en las inmediaciones del bisel, que se abre rápidamente a medida que se aleja del filo. Sólo en las aristas puede presentar una trama un poco más cerrada lejos del bisel. Hay poca articulación entre las zonas modificadas. Tiene un aspecto granuloso y poco brillante que recuerda al producido durante el trabajo de materias abrasivas. Sin embargo, las partes más cerradas tienen un ligero volumen que lo diferencian de las microtopografías de origen exclusivamente abrasivo. Además, pueden observarse otros accidentes aparte de las estrías, como son los microcráteres, pero no los típicos microhoyuelos en forma de cometa.

El aumento en el tiempo de uso incrementa la visibilidad y desarrollo de todas las variables dependientes, persistiendo también la influencia de la granulometría de la materia prima. Así, tras dos horas de siega, los dientes de hoz experimentales presentan unas huellas de uso que difieren escasamente de las descritas anteriormente, aunque ya puede detectarse un ligero desgaste del filo en ciertas piezas bajo la lupa binocular y las melladuras son relativamente más abundantes. Por otra parte, en aquellas zonas de mayor desgaste se puede observar un ligero lustre a bajos aumentos.

Bajo el microscopio el desgaste del filo sigue siendo moderado, faltando en gran parte del filo de las piezas distales y proximales, mientras que es muy marginal pero continuo en las mesiales. Las características de las estrías y el pulido son equivalentes. Siguen sin invadir las depresiones de las muescas. En este caso tienen una trama media en la zona del bisel y existe una mejor articulación entre las distintas zonas modificadas. 
Con 180 minutos o 3 horas de trabajo, el pulido penetra hacia el interior de la pieza de forma más considerable, entre 100 y $700 \mathrm{mi}-$ cras, pero debemos tener en cuenta que en las zonas más profundas presenta una trama completamente abierta. Tiene un brillo moderado y escaso volumen, acompañándose de microcráteres, por lo que su aspecto sigue recordando el contacto con otros materiales abrasivos. Al igual que sucede con el desgaste, las piezas distales y proximales presentan huellas de uso mucho más discretas.

A partir de las 4 horas de trabajo se observa la presencia de huellas de uso más desarrolladas. En los dientes de grano grueso todavía no se observa el desgaste con la lupa binocular, pero en el resto sí. También en este caso es visible un ligero lustre en las partes más salientes de los dientes. Al microscopio, el desgaste sigue siendo marginal, pero continuo a lo largo de todo el bisel. Sólo las dos piezas extremas de la hoz tienen segmentos discontinuos en el interior de las melladuras. Las estrías aumentan en densidad, agrupándose en haces. Son mayoritariamente cortas y de fondo oscuro, aunque es más habitual observar líneas de pulido y accidentes lineales finos y brillantes. En general son paralelas al filo, aunque las de la pieza distal son ligeramente oblicuas, lo que es lógico debido a la curvatura del enmangue.

El pulido continúa con una distribución irregular, penetrando entre 0,7 y los $2 \mathrm{~mm}$ hacia el interior (Tabla 1). Su trama es cerrada en algunos segmentos del bisel, aunque sigue siendo media, con un buen reticulado. Esto confiere a la superficie un aspecto más ondulado y suavizado, pues los microcráteres van desapareciendo con el mayor desarrollo de la trama. Además, en algunas de las zonas con trama cerrada se pueden detectar algunos microhoyuelos. En ciertos casos, el pulido está más desarrollado en la cara ventral que en la dorsal. Generalmente, esto sucede con las piezas de ángulo de filo más obtuso, de manera que la zona dorsal, normalmente más abrupta, permite una peor penetración. Tampoco debemos olvidar que la rugosidad de la materia prima sigue siendo un factor importante para el desarrollo de los estigmas.

A las 6 horas de trabajo, las huellas de uso tienen un buen desarrollo bajo el instrumental óptico, pero que todavía no son visibles a sim- ple vista (Fig. 9). En la lupa binocular se observa un buen redondeado del filo, el pulido es visible en las partes más salientes y algunas melladuras en media luna se destacan de los filos retocados. Observado bajo el microscopio, el desgaste es continuo y ligeramente más desarrollado que en ocasiones anteriores. Las estrías son abundantes, predominando las de fondo oscuro agrupadas en haces, confiriendo a la superficie un aspecto erosivo. El pulido es continuo, aunque de penetración irregular, destacando su mayor desarrollo en las aristas de los retoques. En el bisel puede observarse una delgada franja de trama cerrada cercano al milímetro. La trama también puede ser cerrada en las aristas, y si no, es media o abierta, penetrando ya en algunos casos más de $2 \mathrm{~mm}$. Todavía se observan los microcráteres, y van siendo comunes los microhoyuelos. Es reflectante, con volumen ondulado y bien reticulado.

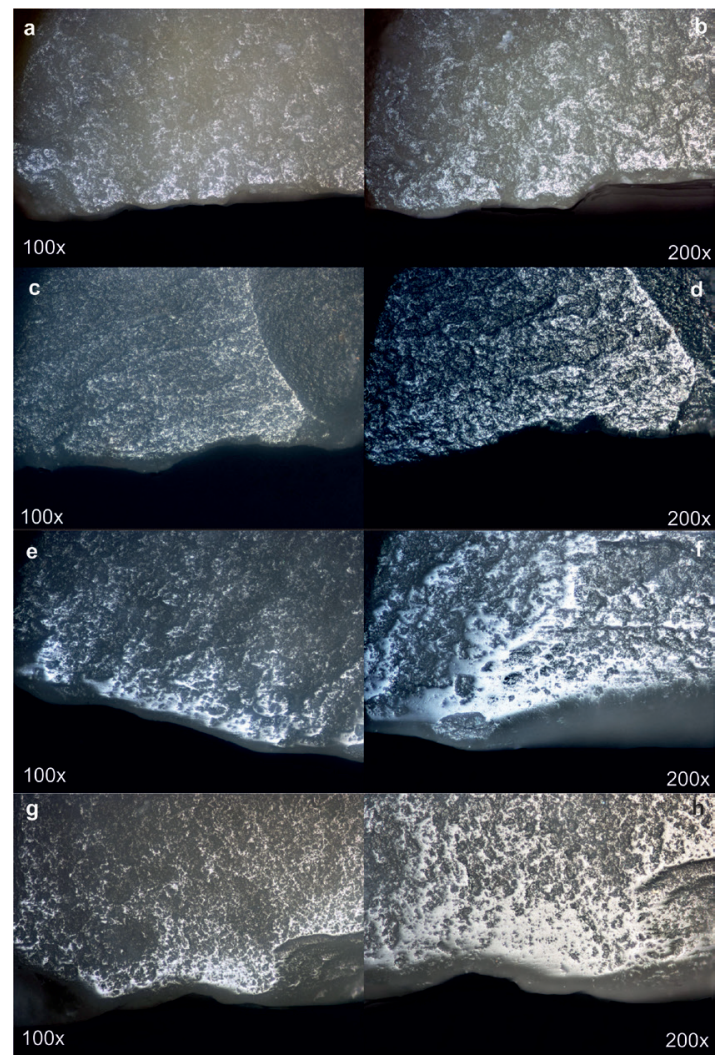

Figura 9. Diversos ejemplos de huellas de uso producidas en los elementos de hoz experimentales empleados en la siega de trigo: a y b: 50 minutos a 100X y 200X respectivamente; c y d: 120 minutos a $100 \mathrm{X}$ y $200 \mathrm{X}$; e y f: 480 minutos a $100 \mathrm{X}$ y 200X; g y h: 720 minutos a $100 \mathrm{X}$ y $200 \mathrm{X}$. 
Tras 8 horas de siega, puede observarse un ligero lustre a simple vista solo en las piezas de grano fino y medio. Los accidentes lineales se combinan: estrías cortas y oscuras y largas y brillantes, también microhoyuelos formando bandas lineales de orientación paralela al filo. El pulido va cerrando su trama en una zona más significativa del bisel, pues hay segmentos donde puede llegar a los $3 \mathrm{~mm}$ (Tabla 1). También las tramas medias y abiertas penetran más, sobrepasando largamente los $5 \mathrm{~mm}$. En general, el aspecto de las superficies es el típico de corte de vegetales no leñosos, brillante, bombeado, aunque sigue sorprendiendo un cierto aspecto erosivo.

Con 10-12 horas de trabajo tampoco se introducen novedades destacadas (Fig. 9). Aunque los dientes de hoz experimentales ya comienzan a mostrar un ligero lustre, todavía no puede compararse con la gran mayoría de las piezas de origen arqueológico. Sólo cabe reseñar que la distinta rugosidad de los sílex sigue propiciando diferencias notables. Los pulidos tienen además un desarrollo diferencial en cada muesca, pues siempre hay una zona de la misma donde la trama es sensiblemente más cerrada que en la otra. Esto se debe a la cinemática del trabajo, pues aquella parte del diente sobre la que se inclina el tallo tiene un mayor rozamiento y por tanto más oportunidades de contacto que la otra.

Por otro lado, los resultados obtenidos en las hoces empleadas en la siega de esparto también están mediatizados por las características de la materia prima empleada y el tiempo de utilización (Fig. 10). Así, las piezas usadas durante 50 minutos tienen un desgaste mínimo o inexistente. Hay melladuras bifaciales abundantes, de terminación afinada, o en media luna que pueden presentarse aisladas o formando pequeños grupos. La mayor presencia de las terminaciones abruptas o reflejadas quizá pueda relacionarse con la mayor resistencia de los tallos de esparto con respecto a los de trigo.

Las estrías son escasas, cuando no inexistentes, mientras que el pulido tiene una distribución marginal, de sólo 100 micras. Hay que reseñar que muestra unas claras características que lo asimilan al corte de vegetales no leñosos: distribución bifacial más o menos simétrica en función del ángulo del filo, trama media, con las zonas bien encadenadas, brillante, con volumen y sin aspecto abrasivo, aunque irregular. Es decir, son mucho menos frecuentes los accidentes lineales, los microcráteres o los microhoyuelos.

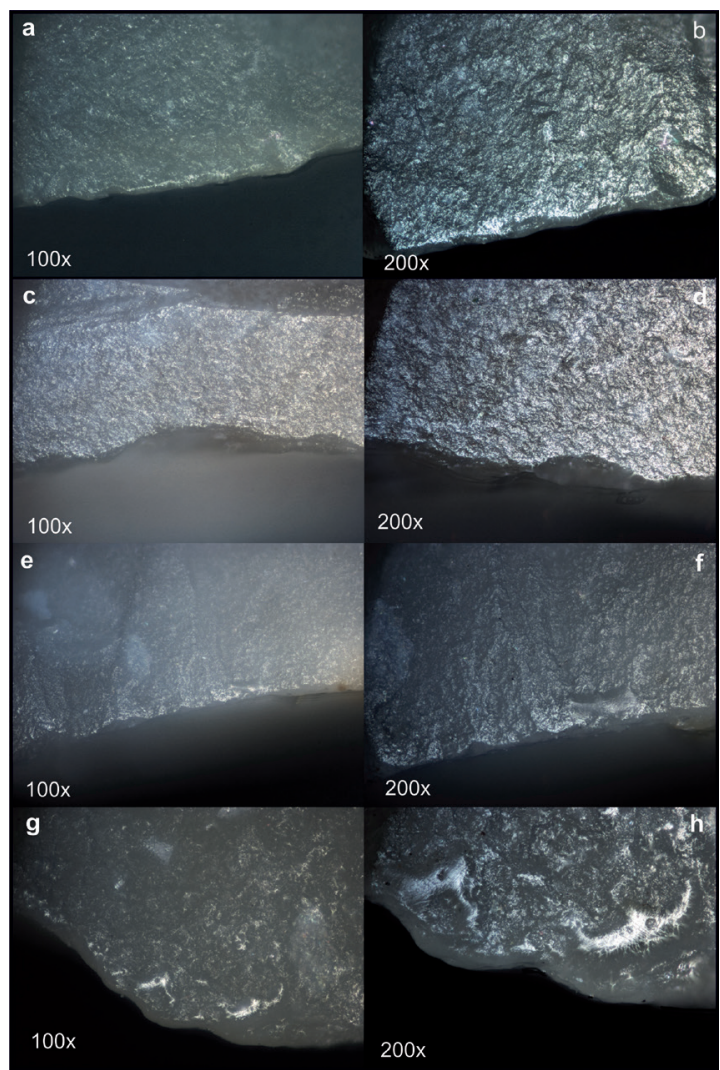

Figura 10. Diversos ejemplos de huellas de uso producidas en los elementos de hoz experimentales empleados en la siega de esparto: a, b, c y d: 50 minutos en dos piezas a 100X y 200X; e, f, g, h:

120 minutos en dos piezas a $100 \mathrm{X}$ y $200 \mathrm{X}$.

Con 120 minutos de siega de esparto se puede observar un ligero brillo en las partes salientes de los dientes con la lupa binocular. Hay melladuras aisladas, unifaciales o bifaciales, de terminación reflejada. Al microscopio apenas se detectan estrías, mientras que el pulido sigue siendo marginal y de penetración muy irregular, alcanzando las 600-1000 micras de profundidad. Sin embargo, este pulido es continuo a lo largo del filo, con una trama cerrada en el mismo bisel, aunque ésta se abre rápidamente al alejarse del mismo. Es brillante, bien articulado, aunque por zonas presenta un aspecto plano, propio del contacto con una materia más dura.

Por su parte, los resultados obtenidos en el estudio de las piezas arqueológicas han permitido realizar diversas agrupaciones, que atienden fundamentalmente a la posibilidad o no de analizar los elementos y al grado de uso que ha podido advertirse en ellos. Así: 
- Una primera agrupación integrada por dos elementos de hoz de la Lloma Redona, procedentes de la unidad estratigráfica superficial, en los que ha sido imposible determinar la presencia de huellas de uso dado el alto grado de alteración de las superficies como consecuencia de procesos térmicos y postdeposicionales.

- Una segunda agrupación de 5 elementos -de Tabayá (n $\left.{ }^{\circ} 787\right)$ y Lloma Redona -87/21/Sup/; 91/Sup; 91/IIB y 91/III- en los que, aunque reproducían plenamente los rasgos morfológicos de los elementos de hoz con retoque de delineación denticulada y de acomodación mediante fracturas por percusión en el dorso y ejes, no presentaban huellas de ningún tipo, ni alteraciones considerables que impidieran su documentación. Se trata, por tanto, de cinco elementos manufacturados pero no usados.

- El tercer grupo está integrado por 6 elementos -1 del Pic dels Corbs-94, $\mathrm{n}^{\circ}$ 47; 1 de Lloma de Betxí-96; 2 de Lloma Redona 87 y 91, así como otros dos de la serie de nueve elementos del conjunto cerrado de Tabayá (no 849 y 852) (Fig. 11)- que presentaban un desgaste moderado en ambas caras del filo, dispuesto a lo largo del mismo, caracterizado por un pulido de distribución irregular, de trama cerrada, poco profunda, aunque superior a las 100 micras a 100 aumentos, y un cierto redondeado del bisel en algunos puntos. La trama cerrada se localiza en los extremos más salientes de los dientes y a continuación se va abriendo paulatinamente a escasa distancia del filo. El pulido es brillante, de aspecto voluminoso y líquido. Se observa la presencia de algunas estrías de fondo oscuro, dispuestas de forma paralela al filo, así como microcráteres de tipo abrasivo. En el caso concreto del elemento de la Lloma de Betxí, se ha documentado la práctica del reavivado de las muescas, observable en un grado diferencial de desarrollo del pulido bastante evidente. Además, en algunos elementos, especialmente de Tabayá, se observa procesos de alteración por afecciones térmicas que han incidido en la conservación y/o desarrollo del pulido. Como conclusión, se puede inferir que estamos ante elementos que han desarrollado una labor de corte o siega de vegetales no leñosos, posiblemente gramíneas. Se trata de elementos usados durante un número no muy amplio de horas, quizá similar al de piezas del programa experimental $-10 / 12 \mathrm{~h}-$, y que, en algunos casos, han sido reavivados para alargar su vida útil.

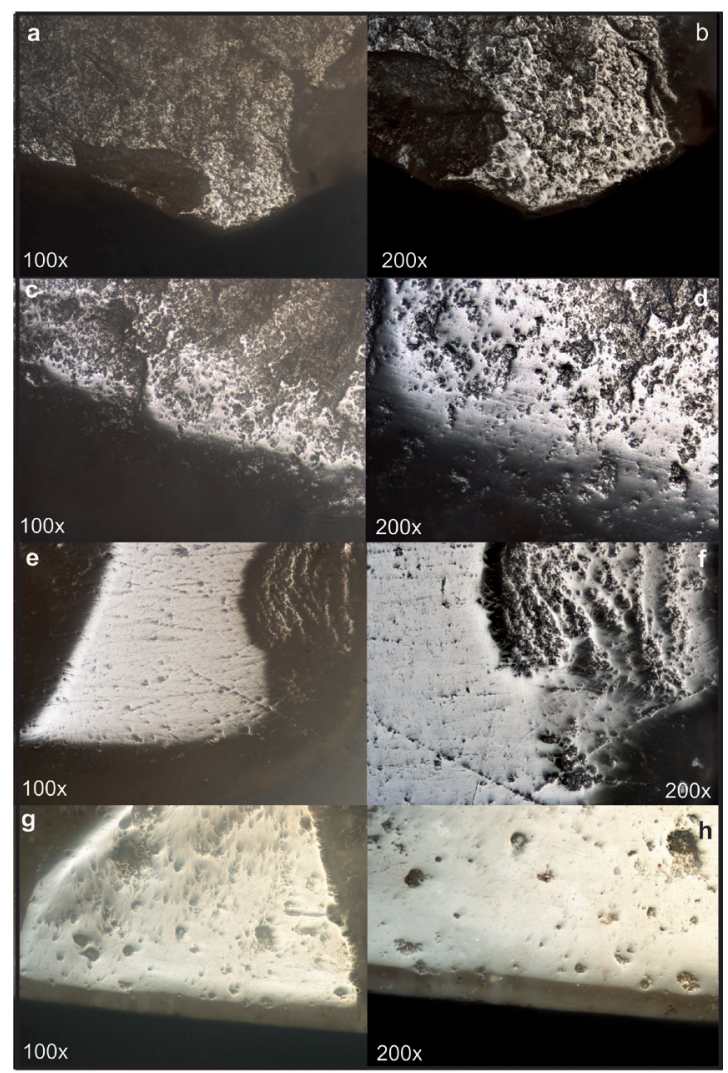

Figura 11. Huellas de uso de siega de cereales procedentes del yacimiento de Tabayá, con diversos grados de desarrollo a $100 \mathrm{X}$ y 200X; a y b: Tab. 5; c y d; Tab 1; d y e Tabayá C11 sector B1 IV; fy g Tab 4.

- Agrupación integrada por un total de 39 elementos -2 de la Muntanya Assolada-96, 1 de Lloma de Betxí-96, 1 de Pic dels Corbs ( $\left.n^{\circ} 48\right), 8$ de Tabayá, siendo 7 de ellos los integrantes del conjunto cerrado interpretado como hoz $\left(\mathrm{n}^{\mathrm{o}} 848,850,851,853,854\right.$, 855 y 856); 15 elementos documentados en deposición primaria del Cerro de El Cuchi1lo, 9 elementos de la Lloma Redona de diversos estratos y 3 de Cabezo Redondo ( ${ }^{\circ}$ 73, 84 y 187)-, en los que se documenta un desgaste bastante acusado del bisel, con un 
pulido continuo, muy profundo, localizado en ambas caras del filo, dispuesto de forma longitudinal. Es de trama muy cerrada con un bisel completamente redondeado y embotado. El pulido es brillante, con volumen y de aspecto líquido. Se extiende de forma homogénea con diferente profundidad según la pieza, pero siempre como mínimo llegando al límite interior de las muescas -3 ó $4 \mathrm{~mm}$-. En alguna se llega a superar los $11 \mathrm{~mm}$. La zona pulida está surcada de estrías, unas colmatadas, de tipo abrasivo, bien de fondo oscuro, bien formada por la sucesión de microhoyuelos. Se observan además, algunas estrías dispuestas de forma perpendicular y oblicua al filo, para las que consideramos un origen postdeposicional. Los elementos de Muntanya Assolada, Lloma de Betxí y de Tabayá - nº 848, $850,853,854$ y 856 - presentan reavivados en algunas de las muescas, observables de forma evidente en el desgaste diferencial, bastante significativo, entre la superficie del negativo de lascado de la nueva muesca y la superficie del bisel. En definitiva, se trata de un conjunto de soportes utilizados durante un número muy significativo de horas en trabajos de siega. La dificultad reside en concretar durante cuánto tiempo fueron empleados, aunque algunos trabajos recientes para elementos de hoz registrados en contextos neolíticos han evidenciado que la profundidad y características de las tramas podría ser significativo para determinar el tiempo de uso hasta su abandono (Goodale et al. 2010).

Por tanto, la comparación entre las huellas de uso del programa experimental, y las documentadas en los elementos arqueológicos, permite inferir que, aquellos dientes de hoz usados se destinaron a la siega de vegetales blandos no leñosos, con mucha probabilidad cereales, sobre todo teniendo en cuenta la incidencia de accidentes como los microcráteres, microhoyuelos y las estrías de diversa naturaleza.

En el conjunto experimental se observó que la cara del elemento que estaba más en contacto con la tierra es la que presenta un mayor desgaste. No obstante, este factor se diluye enormemente cuando los elementos de hoz han sido usados durante un número de horas considerable. También se constató la práctica de reavivados de los filos. Esta circunstancia pudo realizarse directamente sobre las piezas enmangadas, como parece deducirse del material procedente de los conjuntos cerrados de Tabayá y El Cuchillo. O, por el contrario, cuando las armaduras estaban desenmangadas. Esta última circunstancia también puede propiciar que al volverse a insertar se cambiase la orientación y disposición en el mango de alguna de ellas. Esto implicaría muchas dificultades en cualquier intento de detectar estas circunstancias en un análisis funcional, pero es algo muy plausible para unos elementos cuyo uso fue tan prolongado en el tiempo. Por otra parte, en el programa experimental se realizaban los cortes a una distancia de entre siete y diez centímetros del suelo y sin embargo, son bastante significativos los estigmas relacionados con contacto con materias abrasivas. Este dato viene a añadir un nuevo matiz a otras observaciones experimentales que vinculan estas huellas de uso con la práctica de una siega a ras de suelo. En todo caso, el número de horas de trabajo debió ser muy elevado y las posiciones adoptadas por las personas que segaban, así como las condiciones de los campos pudieron variar, con los consiguientes reflejos en la distribución y densidad de cada variable dependiente.

\section{Conclusiones}

Con anterioridad a este trabajo considerábamos que los dientes de hoz, como útil característico de las sociedades de la Edad del Bronce, podrían haber sido usados en diversas labores de corte y aserrado, además de los trabajos de siega, ya señalados por los estudios funcionales desde hace décadas. Sin embargo, la información obtenida a partir del desarrollo del programa experimental expuesto, del estudio traceológico de elementos de trillo actuales y de un buen conjunto de dientes de hoz arqueológicos viene a validar que, preferentemente, fueron utilizados como armaduras de hoces en la siega de vegetales no leñosos. Pero, al mismo tiempo, se pueden inferir otra serie de propuestas que se concretan en:

1. Aunque otros trabajos traceológicos han evidenciado que este tipo de piezas también pudieron emplearse como elementos 
para el trillado (Gibaja 2003a; Gibaja et al. 2012a; Clemente et al. 2014), nuestros datos han puesto de manifiesto que las huellas de uso de los elementos de trillo, insertados en tablas de madera y empleados hasta hace poco, no se asemejan a las piezas arqueológicas observadas. Ahora bien, sería importante seguir experimentando para profundizar en los diferentes tipos de trillo (y sobretodo de procesos de trillado) que pudieron efectuarse durante la Edad del Bronce, en especial, en un trillado manual de corte sobre el suelo que pueda generar huellas algo más abrasivas (Gibaja 2003a), difícilmente diferenciables de una siega a ras de suelo. En este sentido, queremos destacar que la importancia de distinguir entre un trillado empleando tablas de madera y tracción humana o animal, frente al mismo trabajo mediante corte manual o golpeo de los haces reside, no sólo en las diferencias existentes en los procesos de trabajo que conllevan, sino, sobre todo en las implicaciones en la organización social del trabajo, en las prácticas económicas y de magnitud en la producción de cereales que se derivan de su empleo.

2. El programa experimental ha permitido constatar el proceso de desgaste de los filos en función del tiempo de uso de las hoces. Desde los 50 minutos de su empleo ya empiezan a reflejarse algunos pulidos y microdesconchados que permitirían diagnosticar su empleo en estos menesteres. Ahora bien, es a partir de 2 horas de uso cuando pueden observarse y definirse con total claridad. Desde las 10-12 horas, ya se puede detectar un cierto lustre a simple vista, aunque no tan desarrollado como los habitualmente observados en la mayoría de las piezas arqueológicas. Para conseguir resultados similares a los constatados en las piezas arqueológicas sería necesario un número de horas de trabajo mucho más elevado, pudiendo ser extrapolables las estimaciones efectuadas por Goodale y otros (2010: 1197-1200, Fig.4), a partir del estudio comparativo entre elementos experimentales y piezas arqueológicas del sudoeste asiático. Estos autores determinan a través de la cuantificación de la extensión de los pulidos según el tiempo de trabajo en piezas experimentales empleadas hasta 16 horas, que algunos de los soportes arqueológicos estudiados pudieron estar en uso hasta 187 horas, aunque la media del conjunto de piezas arqueológicas analizadas con diferente grado de uso se situaría en torno a las 55 . Ello implica que la vida útil de los soportes de sílex en labores de siega es amplia, pudiendo ser utilizados en bastantes jornadas de trabajo y siegas. Además cada armadura podría ser sustituida en las hoces de forma individual y, por tanto, su producción tampoco debía de ser necesariamente muy elevada. Estos aspectos podrían justificar la relativa escasa presencia de dientes de hoz en los yacimientos arqueológicos de la Edad del Bronce.

3. Por otra parte, la gran variabilidad de topografías de los sílex que hemos documentado muestra que este parámetro no constituía una condición importante para la selección de las materias primas. Cualquier tipo de sílex con unas condiciones mínimas de tallado, podría ser empleado. Por tanto, para las comunidades de la Edad del Bronce no sería necesario invertir tiempo en la búsqueda y selección de materias de buena calidad.

4. Por otra parte, no se puede descartar que existieran personas especializadas en la producción de estas piezas, ya en el propio asentamiento ya como artesanas itinerantes. La presencia de dientes de hoz sin usar, constatados en numerosos yacimientos, debe responder al almacenamiento de los útiles en previsión de futuras necesidades.

5. También se ha vuelto a constatar que la posición de los elementos dentro de la hoz incide en el mayor o menor desgaste de las partes activas. En nuestro programa experimental, son los dientes de hoz distales de un mango ligeramente curvo, los que menos se desgastan, aunque presenten en ocasiones mayor incidencia de accidentes lineales y de abrasión. Ello está en íntima relación con el mayor o menor contacto con las mieses. Al mismo tiempo, otro aspecto que también repercute en el proceso de formación de las 
huellas de uso es la orientación de cada uno de los dientes de hoz. La cara del elemento que esté más en contacto con la tierra, presenta un mayor desarrollo de las huellas de uso. No obstante, este factor se diluye enormemente cuando los elementos de hoz han sido usados durante un número de horas considerable -bastante superior, claro está, a las experimentaciones aquí expuestas-. Las observaciones realizadas en las piezas arqueológicas así lo evidencian y ya hemos comentado alguno de los factores que pueden influir en esa circunstancia.

6. De enorme interés es la documentación en los soportes arqueológicos de múltiples reavivados de las muescas del filo con el objetivo de mantener y alargar la vida útil del instrumento. Es una prueba que viene a apoyar la idea de que los grupos humanos de esta época aprovechaban los productos hasta su agotamiento definitivo, potenciando su mantenimiento e incluso, a veces, su reciclado (Jover 1998). Esto permite inferir la reposición de elementos sobre los mismos soportes una vez que los existentes están enormemente agotados o se han perdido por otras causas. El ejemplo de los elementos documentados en la hoz de Tabayá es una prueba clara, pues no solo se ha constatado el reavivado de los retoques de ciertas piezas, sino que existen diferencias en el desarrollo de las huellas de uso del conjunto, indicando que unas estuvieron en activo más tiempo que otras.

7. El reducido tamaño de los asentamientos en el ámbito del Bronce Valenciano -los de mayor extensión no sobrepasarían los 0,4 $\mathrm{Ha}$, mientras la mayor parte no superarían las $0,06 \mathrm{Ha}$ (Jover et al. 2016)- no impli- caría la necesidad de cultivar cereales en grandes extensiones de terreno, por lo que en muy pocas jornadas de trabajo se podrían haber efectuado las labores de siega. De ese modo, las hoces podrían ser guardadas y mantenidas en los ámbitos domésticos, como así queda atestiguado en diversos yacimientos antes señalados. Destaca en este caso el enclave de Cabezo Redondo, que tiene una extensión mucho mayor que el resto y donde se documentan diversos conjuntos de dientes de hoz almacenados en el interior de vasijas en distintos departamentos (Soler García 1987). Otra cuestión es su escasa presencia en asentamientos de gran tamaño-superiores a 1,5 Ha- del ámbito argárico como Fuente Álamo (Risch 2002) o La Bastida de Totana (Lull et al. 2015: 113-117), más aún si lo comparamos con el elevado número de instrumentos de molienda registrados (Risch 2002). Ello podría ser indicativo de que dichas poblaciones no efectuarían de forma directa las labores de siega de los cereales, pero sí tendrían la capacidad de centralizar el cereal para su transformación en harina.

En cualquier caso, y a pesar de los estudios efectuados sobre los elementos denticulados de numerosos yacimientos de la Edad del Bronce, todavía se adolece de estudios traceológicos de la globalidad del registro lítico tallado. Esta asignatura pendiente es la que, en nuestra opinión, permitirá dar un salto cualitativo de enorme importancia, no sólo para poder comparar con registros líticos de otros contextos sino, sobre todo, para determinar qué papel desempeñaron las producciones líticas talladas en los grupos campesinos de finales de la Prehistoria.

\section{Bibliografía}

Alonso, N. (1999): De la llavor a la farina. Els procesos agrícoles protohistòrics a la Catalunya Occidental. Monographies d'Archéologie Méditerranéenne 4. Lattes.

Alonso, N.; Clemente, I.; Ferrer, C.; Gené, M.; Gibaja, J.F.; Juan, N.; Junyent, E.; Lafuente, A.; López, J.B., Llussà, A.; Mirantd, J.; Miró, J.M.; Morán, M.; Roca, J.; Ros, M-T.; Rovira, C. y Tartera, E. (2000): Les Roques del Sarró (Leida, Segrià): Evolució de l'assentament entre el 3600 cal a.n.e. i el 175 a.n.e. Revista d'Arqueologia de Ponent, 10 : 103-173.

Anderson, P.C. (1992): Experimental cultivation, haverst and threshing of wild cereals and their relevance for interpreting the use of Epipaleolithic and Neolithic artefacts. Préhistoire de l'agriculture. Nouvelles approches expérimentales et ethnographiques. Monographie du CRA n ${ }^{\circ}$ 6: 179-210. 
- (1994): Reflections on the significance of two PPN typological classes in light of experimentation and microwear analysis: flint "sickles" and obsidian "Çayönu" tools". En Gebel, H. G. y Kozlowski, S. K. (eds.), Neolithic Chipped Stone Industries of the Fertile Crescent. Studies in Early Near Eastern Production, Subsistence, and Environment 1, ex oriente, Berlin: 61-82.

Anderson P.; Deraprahamian, G. y Willcox, G. (1991): Les premières cultures de ceréales sauvages et domestiques primitives au Proche-Orient néolithique: résultats préliminares d' expériences à Jalès (Ardèche). Cahiers de l'Euphrate, 5-6. París.

Arnal, J; Prades, H. y Fletcher, D. (1968): La Ereta del Castellar (Villafranca del Cid, Castellón). Trabajos Varios del S.I.P. 35.Valencia.

Astruc, L.; Ben Tkaya, M. y Torchy, L. (2012): De l'efficacité des faucilles néolithiques au Proche-Orient : approche expérimentale. Bulletin de la Société Préhistorique Française 109 (4): 671-687.

Barrachina, A. M. (2012): Indesinenter: permanencia y cambio. El Pic dels Corbs como modelo de interpretación de la edad del bronce en el norte del País Valenciano. Serie de Prehistòria i Arqueología, Servei d'Investigacions Arqueològiques i Prehistòriques. Castelló de la Plana.

Botella, E. (1928): Excavaciones en la Mola Alta de Serelles (Alcoy). Junta superior de Excavaciones Arqueológicas, 94. Madrid.

Carrión, E.; Baena, J.; Iniesta, J. y Blasco, C. (2004): Aproximación a las diferentes técnicas, tipológicas y de explotación de la industria lítica entre los horizontes Protocogotas y Cogotas I, a través de los datos del Caserío de Perales del Río (Getafe, Madrid). En En Hernández, L. y Hernández M. S. (eds.), La Edad del Bronce en tierras valencianas y zonas limótrofes, Villena: 603-612.

Clemente, I. y Gibaja, J.F. (1998): Working processes on cereals: an approach through microwear analysis. Journal of Archaeological Science, 25: 457-464.

- y Vila, A. (1999): Análisis funcional de la industria lítica tallada procedente de los sondeos de Gatas, en Castro, P., Chapman, R.w., Gili, S., Lull, V., Micó, R., Rihuete, C., Risch, R. y Sanahuja, M.E. (eds.), Proyecto Gatas 2. La dinámica arqueoecológica de la ocupación prehistórica, Sevilla: 341-346.

Clemente, I; Mazzuco, N. y Soares, J. (2014): Instrumentos para siega y procesado de plantas desde el Calcolítico al Bronce antiguo en Chibanas (Palmela, Portugal). Trabajos de Prehistoria, $71 \mathrm{n}^{\circ} 2: 330-342$. https://doi.org/10.3989/tp.2014.12137

Colominas, J. (1927): La necrópolis de Las Laderas del Castillo (Callosa del Segura, Alicante). Anuari del Institut d'Estudis Catalans, VIII: 12-39.

Cuadrado, E. (1950): Útiles y armas de El Argar. Ensayo de tipología”. Congreso de Arqueología del Sudeste Español, I, Cartagena: 103-116.

De Pedro, M.J. (1984): La industria lítica de la Mola d'Agres (Alicante). Saguntum, 18: 85-106.

- (1998): La Lloma de Betxí (Paterna, Valencia), un poblado de la Edad del Bronce. Trabajos Varios del S.I.P. 98. Valencia.

Enguix, R. (1975): Notas sobre la economía del Bronce Valenciano. Papeles del Laboratorio de Arqueología de Valencia, 11: 141-157.

Escalera, S. (1985): Estudio etnográfico sobre el ciclo del cultivo. Transformación y elaboración tradicionales del trigo en la Sierra Aracena. Campaña 1982-83. Etnografia Española, 5: 7-74.

Fortea, J. (1973) Los complejos Mircolaminares y Geométricos del Epipaleolítico mediterráneo español. Memorias del Seminario de Prehistoria y Arqueología, 4. Salamanca.

Furgús, J. (1937): Col.lecció de Treballs de P.J. Furgús. Trabajos Varios del SIP, 5. Valencia.

Gibaja, J.F. (1994): Análisis funcional del material lítico de las sepulturas de la Bòbila Madurell (Sant Quirze del Vallès, Vallès occidental). Universitat Autónoma de Barcelona. Tesi de llicenciatura.

- (1999): Análisis del registro lítico de El Recuenco (Cervera del Llano, Cuenca). Archivo de Prehistoria Levantina, XXIII: 197-208.

- (2002): Análisis funcional del registro lítico de Fuente Álamo (Almería). En Risch, R. (ed.): Recursos naturales, medios de producción y explotación social. Un análisis económico de la industria lítica de Fuente Álamo (Almería), 2250-1400 ANE: 163-177.

- (2003a): Hoces líticas argáricas del Sudeste peninsular. Revista Atlántico Mediterránea de Prehistoria y Arqueología Social, 6: 115-136.

- (2003b): Comunidades neolíticas del noreste de la Península Ibérica. Una aproximación socio-económica a partir del estudio de la función de los útiles líticos. BAR International Series 1140. Oxford.

- (2004): Estudio traceológico de las hoces argáricas del asentamiento de Fuente Álamo (Almería). La Edad del Bronce en las tierras valencianas y zonas limitrofes, Alicante: 487-492. 
Gibaja, J.F.; Palomo, A.; Terradas, X. y Clop, X. (2004): Útiles de siega en contextos funerarios del 3500$1500 \mathrm{cal}$ ANE en el noreste de la Península Ibérica: el caso de las grandes láminas de sílex. Cypsela, 15: 187-195.

Gibaja, J. F.; Crespo, M.; Delibes de Castro, G.; Fernández, J.; Fraile, C.; Herrán, J. I.; Palomo, A. y Rodríguez, J. A. (2012a): El uso de trillos durante la edad del cobre en la meseta española. Análisis traceológico de una colección de denticulados de sílex procedentes del 'recinto de fosos' de el casetón de la era (Villalba de los Alcores, Valladolid)". Trabajos de prehistoria 69 (1): 133-148. https://doi.org/10.3989/ tp.2012.12084

Gibaja, J.F.; Ibáñez, J.J.; Rodríguez, A.; González, J.E.; Clemente, I.; García, V. y Perales, U. (2010): Estado de la cuestión sobre los estudios traceológicos realizados en contextos mesolíticos y neolíticos del sur peninsular y noroeste de África, Os últimos caçadores-recolectores e as primeiras comunidades produtoras do sul da Península Ibérica e do norte de Marrocos, Universidad do Algarve, Portugal:181-190.

Gibaja, J.F.; Peña-Chocarro, L.; Ibáñez, J.J.; Zapata, L.; Rodríguez, A.; Linstädter, J.; Pérez, G.; Morales, J.; Gassin, B.; Carvalho, A.F.; González, J. E. y Clemente, I. (2012b): A los dos lados del Estrecho: las primeras hoces líticas y evidencias de agricultura en el sur de la Península Ibérica y el norte de Marruecos. Una perspectiva de futuro, Congrés Internacional Xarxes al Neolític- Neolithic Networks, Rubricatum 5, Gavà: 87-93.

Goodale, N.; Otis, H.; Andefsk, y. W.; Kuijt, I.; Finlayson, B. y Bart, K. (2010): Sickle blade life-history and the transition to agruculture: an early Neolithic case study from Southwest Asia. Journal of Archaeological Science, 37: 1192-1201. https://doi.org/10.1016/j.jas.2009.12.017

González, J.E. e Ibáñez, J.J. (1994): Metodología de análisis funcional de instrumentos tallados en sílex. Kobie, XXI: 111-129.

Gutiérrez, C. (1993): Piezas con lustre del Bronce Final de Perales del Río (Madrid). I Congreso de Arqueología Peninsular. Oporto.

Harrison, R.J. y Meeks, D. (1987): Gloss on flint tool from the Bronze age settlement of Moncín, Borja (provincia de Zaragoza). Madrider Mitteilungen, 28: 44-50.

Hernández, M.S. y López, J.A. (2010): La muerte en el Argar alicantino. El Tabaià como paradigma. En Pérez, A. y Soler, B. (coord.). Restos de vida, restos de muerte, Valencia: 221-228.

Hernández, M.S. y Pérez, J.M. (2005): En busca de nuestros orígenes. El poblamiento prehistórico de Sax. Historia de Sax, I: 103-128.

Hernández, M.S.; Simón, J.L. y López, J.A. (1994): Agua y poder. El cerro de El Cuchillo (Almansa, Albacete). Patrimonio Histórico-Arqueología, 9. Toledo.

Hernández, M.S.; García, G. y Barciela, V. (2016): Cabezo Redondo (Villena, Alicante). Villena.

Ibáñez, J. J.; González, J. E. y Gibaja, J. F. (2014): Discriminating wild vs domestic cereal harvesting micropolish through laser confocal microscopy. Journal of Archaeological Science, 48: 96-103. https:// doi.org/10.1016/j.jas.2013.10.012

Jover, F.J. (1994): La industria lítica del yacimiento del Cerro de El Cuchillo. En Simón, J.L., Hernández, M. y lópez, J.A. 1994: 165-174.

- (1997): Caracterización de las sociedades del II milenio ANE en el Levante de la Península Ibérica: cultura, modos de trabajo, modo de vida y formación social. Tesis doctoral. Universidad de Alicante. http://rua.ua.es/dspace/handle/10045/6901.

- (1998): Medios de producción líticos durante la Edad del Bronce en la Hoya de Alcoi (Alicante). Recerques del Museu d'Alcoi, 7: 107-130.

- (1999): Una nueva lectura del "Bronce Valenciano". Universidad de Alicante.

- (2008): Caracterización de los procesos de producción lítica durante la Edad del Bronce en el Levante de la península Ibérica. Lvcentum, XXVII: 7-32.

- (2014): Cabezo Pardo. El instrumental lítico del asentamiento argárico. En López Padilla, J.A. (coord.), Cabezo Pardo (San Isidro - Granja de Rocamora, Alicante): excavaciones arqueológicas en el yacimiento de la Edad del Bronce: 135-178.

Juan, J. (1985): La hoz de la Edad del Bronce del "Mas de Menente" (Alcoi, Alacant). Aproximación a su tecnología y contexto cultural. Lvcentum, IV: 37-54.

- (2009): El utillaje de piedra tallada en la Prehistoria reciente valenciana. Aspectos tipológicos, estilísticos y evolutivos. Trabajos Varios del SIP, 109. Valencia.

Korobkova, G. (1981): Ancient reaping tools and their productivity in light of experimental tracewear analysis. En Kohl, P.L (ed). The Bronze Age civilization of Central Asia. New York : 325-349. 
— (1992) : Les cycles de l'economie agricole (d'après l'outillage): résultats des analyses expérimentales et tracéologiques. Préhistoire de l'agriculture. Nouvelles approches expérimentales et ethnographiques. Monografie du CRA n ${ }^{\circ}$ 6, París: 271-280.

López-Rodríguez, M.C. (2013): Análisis funcional de las hoces prehistóricas a través de la traceología. Una cuestión experimental. Arqueología y Territorio, 10, p. 1-11.

Lull, V. (1983): La "cultura" de El Argar. Un modelo para el estudio de las formaciones económico-sociales prehistóricas. Akal. Madrid.

—; Micó, R.; Rihuete, C. y Risch, R. (2015): La Bastida y Tira del Lienzo (Totana, Murcia). Ruta Argárica. Guías arqueológicas. Murcia.

Martí, B. (1977): Cova de l'Or (Beniarrés-Alicante). Vol. I, Serie de Trabajos Varios del S.I.P. 51. Valencia. — (1983): La Muntanya Assolada (Alzira,Valencia). Lvcentvm, II: 43-68.

Martínez, G y Afonso, J.A. (2013): La producción lítica tallada de la edad del bronce: aspectos técnicos y tipológicos derivados del análisis de la industria de la Motilla del Azuer (Daimiel, Ciudad Real). Cuadernos de Prehistoria y Arqueología de Granada, 22: 255-286.

Molina, F.J. (2016): El sílex del prebético y cuencas neógenas en Alicante y sur de Valencia: su caracterización y estudio aplicado al paleolítico medio. Tesis doctoral. Universidad de Alicante. Fecha de consulta: 14/02/2018. http://rua.ua.es/dspace/handle/10045/56446

Monteagudo, L. (1956): Hoces de sílex prehistóricas. Revista de Archivos, Bibliotecas y Museos, LXII, 2: 458-534.

Moreno, S. (1942): Apuntes sobre las estaciones prehistóricas de Orihuela. Trabajos Varios del S.I.P., 7. Valencia.

Navarro, J.F. (1982): Materiales para el estudio de la Edad del Bronce en el Valle Medio del Vinalopó (Alicante). Lvcentvm, II: 19-70.

- (1986): La Lloma Redona. Arqueología en Alicante 1976-86. Alicante: 102-103.

Ollé, A. y Vergès, J.M. (1998): Análisis morfotécnico y funcional de la industria lítica del poblado de Genó. En Maya, J.L., Cuesta, F. y López, J. (eds.), Un poblado del Bronce Final en el Bajo Segre (Lleida). Barcelona: 203-222.

Palomar, V. (1995): La Edad del Bronce en el Alto Palancia. Segorbe.

Palomo, A.; Gibaja, J. F.; Ortega, D.; Alonso, N.; Marín, D. y Moya, A. (2012): La industria lítica tallada del asentamiento de Minferri (Juneda, Lleida) a finales del III/primera mitad del II milenio cal. BC. Cypsela 19: 103-122.

Pérez Jordà, G. (2013): La agricultura en el País Valenciano entre el VI y el I milenio a.C. Tesis doctoral de la Universidad de Valencia. http://roderic.uv.es/handle/10550/31152

Pericot, L. y Ponsell, F. (1928): El poblado del Mas de Menente (Alcoy). Archivo de Prehistoria Levantina, I: $101-117$.

Picazo, J.V. (1991): Excavaciones arqueológicas en La Sima del Ruidor (Aldehuela, Teruel). Campaña de 1986. Arqueología Aragonesa 1986-1987. Zaragoza: 119-125.

Pla, E. (1958): La covacha de Ribera (Cullera-Valencia). Archivo de Prehistoria Levantina, VII: 1-37.

Ponsell, F. (1926): Excavaciones en la finca Mas de Menente término de Alcoy (Alicante). Junta Superior de Excavaciones Arqueológicas 78. Madrid.

Ramos, J. (1991): El hábitat prehistórico de El Estanquillo, San Fernando. Colección de Temas Isleños. Fundación Municipal de Cultura. San Fernando.

Reynolds, P.J. (1992): Crop yields of the prehistoric cereal types Emmer and Spelt: the worst option. Prehistorie de l'Agriculture: Nouvelles Approches experimentales et Etnographiques, Monographie du CRA, $n^{\circ}$ 6. Paris.

Risch, R. (2002): Recursos naturales, medios de producción y explotación social. Un análisis económico de la industria lítica de Fuente Álamo (Almería), 2250-1400 antes de nuestra era. Iberia Archaeologica 3. Ph. von Zabern. Mainz am Rheim.

Sigaut, F., (1991): Un outil ne sert pas a couper, mais en coupant. Structure, fonctionnement et fonction dans l'analyse des objets. En 25 ans d'études technologiques en prehistoire. XI Rencontres internationales d'archéologie et d'histoire d'Antibes. pp. 21-33.

Siret, L. y Siret, E. (1890): Las primeras edades del Metal en el sudeste de España. Barcelona.

Skakun, N.N. (1992): Agricultural implements in the Neolithic and Eneolithic cultures of Bulgaria". Traces etfonction, les gestes retrouvés. Colloque international de Liège. ERAUL 50. París : 361-369. 
- (1993): Évolution des techniques agricoles en Bulgarie chalcothique (d'après les analyses tracéologiques). Préhistoire de l'agriculture. Nouvelles approches expérimentales et ethnographiques. Monografie du CRA n ${ }^{\circ}$ 6. París: 289-304.

Soler, J.M. (1987): Excavaciones arqueológicas en el Cabezo Redondo. Instituto de Cultura Juan Gil-Albert. Alicante.

Steensberg, A. (1979): Draved: an experiment in Stone Age Agriculture. Copenhagen.

Tarradell, M. (1963): El País Valenciano del Neolítico a la iberización. Ensayo de síntesis. Anales de la Universidad de Valencia, XXXVI. Valencia. 